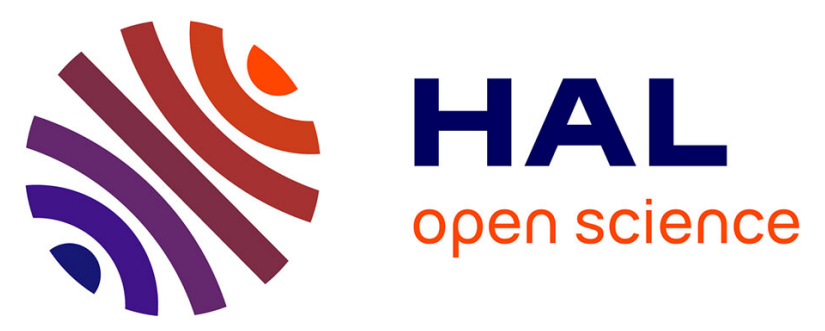

\title{
Geospace perturbations induced by the Earth: The state of the art and future trends
}

A. de Santis, G. de Franceschi, L. Spogli, L. Perrone, L. Alfonsi, E. Qamili, G. Cianchini, R. Di Giovambattista, S. Salvi, E. Filippi, et al.

\section{- To cite this version:}

A. de Santis, G. de Franceschi, L. Spogli, L. Perrone, L. Alfonsi, et al.. Geospace perturbations induced by the Earth: The state of the art and future trends. Physics and Chemistry of the Earth, Parts A/B/C, 2015, 85-86, pp.17-33. 10.1016/j.pce.2015.05.004 . insu-01270603

\section{HAL Id: insu-01270603 \\ https://hal-insu.archives-ouvertes.fr/insu-01270603}

Submitted on 23 Jun 2016

HAL is a multi-disciplinary open access archive for the deposit and dissemination of scientific research documents, whether they are published or not. The documents may come from teaching and research institutions in France or abroad, or from public or private research centers.
L'archive ouverte pluridisciplinaire HAL, est destinée au dépôt et à la diffusion de documents scientifiques de niveau recherche, publiés ou non, émanant des établissements d'enseignement et de recherche français ou étrangers, des laboratoires publics ou privés.

\section{(1) (1) $\$$}

Distributed under a Creative Commons Attribution - NonCommercial - NoDerivatives| 4.0 


\section{Accepted Manuscript}

Geospace perturbations induced by the Earth: the state of the art and future trends

A. De Santis, G. De Franceschi, L. Spogli, L. Perrone, L. Alfonsi, E. Qamili, G. Cianchini, R. Di Giovambattista, S. Salvi, E. Filippi, F.J. Pavon-Carrasco, S.

Monna, A. Piscini, R. Battiston, V. Vitale, P.G. Picozza, L. Conti, M. Parrot, J.-

L. Pinçon, G. Balasis, M. Tavani, A. Argan, G. Piano, M.L. Rainone, W. Liu,

D. Tao

PII:

S1474-7065(15)00042-X

DOI:

http://dx.doi.org/10.1016/j.pce.2015.05.004

Reference:

JPCE 2367

To appear in:

Physics and Chemistry of the Earth

Received Date: $\quad 25$ September 2014

Revised Date: $\quad 4$ April 2015

Accepted Date: $\quad 4$ May 2015

Please cite this article as: De Santis, A., De Franceschi, G., Spogli, L., Perrone, L., Alfonsi, L., Qamili, E., Cianchini, G., Di Giovambattista, R., Salvi, S., Filippi, E., Pavon-Carrasco, F.J., Monna, S., Piscini, A., Battiston, R., Vitale, V., Picozza, P.G., Conti, L., Parrot, M., Pinçon, J.-L., Balasis, G., Tavani, M., Argan, A., Piano, G., Rainone, M.L., Liu, W., Tao, D., Geospace perturbations induced by the Earth: the state of the art and future trends, Physics and Chemistry of the Earth (2015), doi: http://dx.doi.org/10.1016/j.pce.2015.05.004

This is a PDF file of an unedited manuscript that has been accepted for publication. As a service to our customers we are providing this early version of the manuscript. The manuscript will undergo copyediting, typesetting, and review of the resulting proof before it is published in its final form. Please note that during the production process errors may be discovered which could affect the content, and all legal disclaimers that apply to the journal pertain. 
Geospace perturbations induced by the Earth: the state of the art and future trends

A. De Santis ${ }^{1,9,{ }^{*}}$, G. De Franceschi ${ }^{1}$, L. Spogli ${ }^{1}$, L. Perrone ${ }^{1}$, L. Alfonsi ${ }^{1}$, E. Qamili ${ }^{1}$, G. Cianchini ${ }^{1}$, R. Di Giovambattista ${ }^{1}$, S. Salvi ${ }^{1}$, E. Filippi ${ }^{1}$, F.J. Pavon-Carrasco ${ }^{1}$, S. Monna ${ }^{1}$, A. Piscini ${ }^{1}$, R.

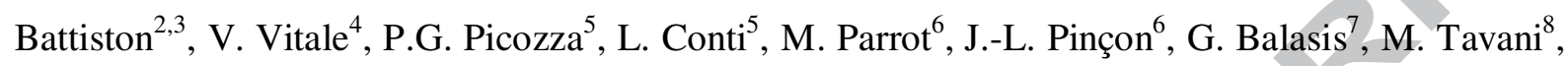

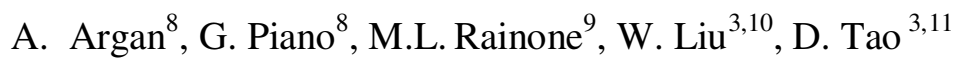

${ }^{1}$ Istituto Nazionale di Geofisica e Vulcanologia, V. Vigna Murata 605, 00143, Roma, Italy; ${ }^{2}$ ASI, Rome, Italy; ${ }^{3}$ Università di Trento, Italy; ${ }^{4}$ INFN, sez. Perugia and ASI Science Data Centre, Frascati, Italy; ${ }^{5}$ UniNettuno, Roma, Italy; ${ }^{6}$ LPC2E/CNRS, France; ${ }^{7}$ IAASARS, National Observatory of Athens, Athens, Greece; ${ }^{8}$ IAPS-INAF, Roma, Italy; ${ }^{9}$ Università G. D'Annunzio, Chieti, Italy; ${ }^{10}$ School of Electronic Information, Wuhan University, China; ${ }^{11}$ Space Science Institute, School of Astronautics, Beihang University, China

* Corresponding author. Tel.: +39 0651860327. E-mail address: angelo.desantis@ingv.it

\section{Abstract}

A systematic multi-parameter and multi-platform approach to study the slow process of earthquake preparation is fundamental to gain some insight on this complex phenomenon. In particular, an important contribution is the integrated analysis between ground geophysical data and satellite data. In this paper we review some of the more recent results and suggest the next directions of this kind of research. Our intention is not to detect a particular precursor but to understand the physics underlying the various observations and to establish a reliable physical model of the preparation 
phase before an impending earthquake. In this way, future investigation will search for suitable fore-patterns, which the physical model of multi-layers coupling predicts and characterizes by quasi-synchronism in time and geo-consistency in space. We also present alternative explanations for some anomalies which are not actually related to earthquakes, rather to other natural or anthropic processes.

Keywords: Earthquake physics; lithosphere-atmosphere-ionosphere coupling; seismic precursors 


\section{Introduction}

Earthquakes are among the most impressive natural phenomena frequently occurring on the planet: their impact on society is enormous because of the huge damages and loss of lives they cause. An earthquake is a dynamic phenomenon that happens because of a slow strain accumulation, usually lasting several years, and culminating with a sudden rupture and displacement of blocks of rock in the rigid lithosphere (e.g. McCaffrey, 2011).

The evolutionary process of earthquakes is rich in complex features, from stochastic to chaotic or pseudo-periodic dynamics, often depending on the different geo-tectonic regime which reflects in the focal mechanisms. Fundamental research in the lithosphere, such as the study of fault rupture mechanics and seismic wave propagation, has been conducted in different regions in the past decades. Many case studies show that there are some seismic anomalies before earthquakes, commonly called seismic precursors (Cicerone et al., 2009), although this term is largely criticised by many scholars, and associated phenomena after earthquakes in terms of ground deformation, active faults (slip rates and geometry), tectonic stress fields and geomagnetic fields. Nevertheless, there is no pragmatic approach to earthquake prediction, and the systematic understanding of the preparation process of earthquakes and their seismic cycles is very limited to date so that, at the moment, earthquake prediction is still considered a "mission - impossible", especially within the seismological community (e.g. Hough 2009 and references therein).

On the other hand, in very recent years, there is an increasing amount of evidence that during some last stages of the long term process of preparation, there could be a transfer of energy between lithosphere and the above layers of atmosphere and ionosphere, so as to introduce the concept of a lithosphere-atmosphere-ionosphere coupling (LAIC) among the three involved layers of the Earth system (e.g. Pulinets et al., 1994, 1997, 1998, 2000; Hayakawa and Molchanov, 2002; Molchanov et al., 2004; Kamogawa, 2006; Pulinets and Ouzounov, 2011). The corresponding variations of the atmospheric, ionospheric and magnetospheric parameters before the main earthquakes could give 
useful information regarding the earthquake preparation process and, if properly identified and isolated, can be used as hints for large impending earthquakes. A promising way to improve the current state of our knowledge on this complex phenomenon is to integrate ground (and possibly seafloor) data analysis with satellite Earth Observation (EO).

Recent studies have shown that numerous geophysical and geochemical parameters, mostly monitored from space, can be possibly associated with earthquakes (Pulinets and Boyarchuk, 2004; Saradjian and Akhoondzadeh, 2011). Fig. 1 shows a sketch of the concept of integrated (ground and satellite) earthquake monitoring system which can be put in practice by means of different kinds of satellites/payloads. One of the preliminary attempts to apply this integrated approach systematically has been within the iSTEP Program (Tsai et al., 2004).

EO by satellites provides the enormous capability of observing regional and global areas of our planet. Satellite sensors acquire a wide range and huge volumes of spatial-temporal measurements capturing a variety of activities produced on Earth or in its interior. Meanwhile, EO provides new possibilities for scientists to investigate the earthquake behaviour by monitoring a broad range of abnormal phenomena reflected in ionosphere and ground displacement from space. This would allow us to improve our understanding of the earthquake preparation process at the global scale by observing the possible ionosphere coupling with lithosphere and atmosphere.

Main focus of this review is to survey the ionospheric and lower magnetospheric perturbations possibly induced by the lithosphere, identified by the analysis of ground-based and space-based data. The review describes the state of the art in the field and points out the scientific challenge to distinguish the different contributions and remove the effects coming from the outer space and manmade technologies. In Section 2 examples of geospace anomalies likely related to earthquakes are given. The list cannot be exhaustive but it is given to provide a sufficient "taste" of the importance of satellite EO for detecting seismic precursors. Section 3 deals with geospace anomalies mainly detected by ground based observations indicating the existence of the lithosphere-geospace link. Geospace signatures of other origins (man-made, atmosphere, outer-space) that can mask the solid 
earth-geospace interaction are faced in Section 4. Finally a discussion and some remarks are given in Section 5.

\section{Geospace anomalies by EO satellites}

\subsection{Lower Magnetosphere}

The study of the trapped particles belts stability is quite important, because these systems are very sensitive to energy releases from the space direction (Solar-terrestrial interaction, cosmic rays) and eventually from the planet (lithosphere, atmosphere). The physics of the Van Allen Belts (VAB) trapping is well understood. Electrons with energies up to tens of $\mathrm{MeV}$ are stably trapped, forming a pair of belts (and sometimes more than two, see Shprits et al., 2013). A dominating source of instability for the inner electron belt is the Whistler-induced Electron Precipitation (WEP) (Rodger et al., 2003), where the resonant interaction between the gyrating electrons and circularly polarized very low frequency (VLF) waves traveling along the magnetic field lines constrains trapped electrons into the loss cone within a time scale of tens of seconds for $3-30 \mathrm{kHz}$ VLF wave frequencies. The electrons precipitations are detected as sudden (few to tens of seconds) increases in the electron flux (electron bursts) by those satellites with orbits below the belts. The solar activity is one dominating cause for belts instability, whose effects should be carefully removed, in order to study possible effects of planetary energy release (lithosphere, atmosphere). Radiation belt electron precipitations were also produced in man-made experiments with ground VLF transmitters (Sauvaud et al. 2008).

Correlations between earthquakes and bursts of $\mathrm{MeV}$ electrons precipitating from the VAB were often reported in the past literature. Experimental data on relatively high-energy charged particle fluxes, obtained from various near-Earth space experiments (MIR orbital station, METEOR-3, GAMMA, SAMPEX, NINA and ARINA satellites) were processed and analyzed by Aleksandrin et al. (2003) who found a 2 to $5 \mathrm{~h}$ precursor effect. A re-analysis of the SAMPEX 
database confirms a 4 h precursor effect (Sgrigna et al., 2005). Similar results have been recently found using data acquired by the NOAA-15 satellite during a period of 11 years (Fidani and Battiston, 2008).

Evidences for a lithosphere-magnetosphere coupling are reported in Battiston and Vitale (2013), where low energy $(<0.3 \mathrm{MeV})$ electron precipitations and earthquakes (magnitude $\mathrm{M} \geq 5$ ) correlations were investigated. The used data were collected with the NOAA POES satellites 15 to 18 during 13 years. The unknown earthquake electromagnetic emission (EME) capture height is a main parameter of this analysis. A range of capture heights was spanned, by associating each earthquakes to an effective L-shell parameter equal to the canonical L, at a nominal height, times $(\cos (l) / \cos (i))^{2}$, with $l$ and $i$ the magnetic latitude and inclination. An excess of electron bursts is found to follow earthquakes with a time delay of $1.25 \pm 0.25$ hours (Fig 2). Anyhow $0.3 \mathrm{MeV}$ have a total drift period around the earth of 4 hours and the absolute correlation timing depends on the burst being detected by the satellite, before or after having traveled one entire orbit.

Analogous results have been found with AGILE satellite data (Tavani et al., unpublished material). Fig. 3 shows the distribution of M5+ earthquakes in the L-shell vs. time diagram accessible by the AGILE satellite in the period August 5 - September 3, 2007. These results underline that operating with a satellite constellation would allow a much more effective coverage improving the correlation efficiency, currently at the level of 5-10\%. Similarly, some new strategies must be studied to extract a useful spatial resolution on the position of the future epicenter, for example by applying a backtracking of L-curves from satellites down to Earth surface.

\subsection{Ionosphere}

Early satellite missions already detected some anomalies before large earthquakes from space: for instance, Larkina et al. (1989) found some possible earthquake-related VLF anomalies from Intercosmos 19 in the upper ionosphere (600-1000 km altitude) just over the earthquake zones. Parrot and Mogilevsky (1989) identified several VLF electromagnetic phenomena recorded at the 
time of some earthquakes, independently from the geostationary satellite GEOS-2 above Africa and from the LEO satellite Aureol-3. Only with a properly designed and specifically built satellite mission for detecting electromagnetic earthquake-related anomalies, such as DEMETER (Detection of Electro-Magnetic Emissions Transmitted from Earthquake Regions), was possible a more systematic search of these possible seismo-electromagnetic precursors from space.

DEMETER is a French micro-satellite operated by CNES and devoted to the investigation of the Earth ionosphere disturbances due to seismic and volcanic activities. Launched on June 29, 2004, it was turned off on 9 December 2010, after more than 6.5 years of scientific mission. Careful statistical studies were performed on the influence of seismic activity on the intensity of low frequency electromagnetic waves in the ionosphere, first based on the first 2.5 years survey of electromagnetic emissions (Němec et al., 2008), and then using the complete DEMETER data set (Píša et al. 2012, 2013). Fig. 4 (right) shows that the normalized probabilistic intensity obtained from the night-time electric field data is below the "normal" level shortly ( $0-4$ hours $)$ before the shallow (depth $<40 \mathrm{~km}$ ) M5+ earthquakes at frequencies of about $1-2 \mathrm{kHz}$. Clear perturbations are observed a few hours before the earthquakes, as another example of "imminent" forecast: they are real, although they are weak and so far only statistically revealed. No similar effects were observed during the day and for deeper earthquakes (Němec et al., 2008). Fig. 4 (left) shows also that the spatial scale of the affected area is approximately $350 \mathrm{~km}$ confirming relatively well the size of the earthquake preparation zone estimated using the Dobrovolsky et al. (1979) formula $\left(\mathrm{r}=10^{0.43 \mathrm{M}} \mathrm{km}\right.$, where $\mathrm{r}$ is the radius of the ideally circular preparation zone and $\mathrm{M}$ is the earthquake magnitude). It must be noted that the frequency of about $1.7 \mathrm{kHz}$, where the decrease is observed, corresponds approximately to the cut-off frequency of the first TM mode (i.e. transverse magnetic mode; EM wave lacks magnetic field component in the direction of propagation) of the Earthionosphere waveguide during the night time. An increase of this cut-off frequency effect would therefore necessarily lead to the decrease of the power spectral density of electric field fluctuations observed by DEMETER in the appropriate frequency range. Since this would also correspond to a 
decrease of the height of the ionosphere, these results would therefore indicate that the height of the ionosphere $(\sim 90 \mathrm{~km})$ above the epicenters of imminent earthquakes is statistically lower than usual. Therefore, this corresponds to an increase of the density in the bottom of the ionosphere above these epicenters. As the EM waves which are propagating in the Earth-ionosphere waveguide are mainly whistlers, this means that it is not a change of their intensities but that their propagation is disturbed above the epicenters of future earthquakes.

Other density changes have been statistically detected at the altitude of the satellite above earthquake epicenters from a few hours up to a few days before the shocks by He et al. (2011) and Li and Parrot (2012, 2013).

CHAMP (CHAllenging Minisatellite Payload) is a German small satellite mission (2000-2010) managed by GFZ for geoscientific and atmospheric research and applications, providing highest quality data for the investigation of geomagnetic and gravity field. Balasis and Mandea (2007) examined, for the first time, CHAMP satellite magnetic and electron density data using a wavelet analysis technique to find out electromagnetic signatures possibly related to the 26/12/2004 Sumatra megathrust (M9.3) earthquake. The authors conclude that, due to the complexity of the ionospheric system, further investigations are required in order to answer the question of whether a series of anomalous signals ("events") found in the data can be associated with the earthquake and to assign their possible usefulness with respect to earthquake development. They strongly envisaged further statistical analysis of CHAMP satellite magnetic and electron density data using highly sensitive signal processing techniques based on linear (wavelet transforms) and nonlinear complex analysis methods based on generalized statistical physics (e.g., Tsallis entropy; Tsallis 1988) as have been applied to preseismic electromagnetic emissions (Kalimeri et al., 2008; Papadimitrou et al., 2008) and, recently, to seismicity studies (Vallianatos and Sammonds, 2013).

Recently automated methods of deriving the characteristics of Ultra Low Frequency (ULF) waves in the magnetosphere have been developed (Balasis et al., 2012, 2013a) and applied to CHAMP 
data. A motivation to investigate this frequency band was for early ULF anomalies detected at a ground stations close to the epicentre of the 1989 M6.9 Loma Prieta earthquake (Fraser-Smith et al., 1990), although recently confuted by Campbel (2009; but see also Fraser-Smith et al., 2011). In Figure 5 we see some events automatically detected on CHAMP satellite magnetic data. Moreover, in the same papers by Balasis et al. $(2012,2013 a)$ a useful software platform based on a combination of wavelet transforms and artificial neural networks has been developed to monitor the wave evolution from the outer boundaries of Earth's magnetosphere through the topside ionosphere down to the surface. The time-frequency analysis tool can be used to detect subtle changes in the spectral properties of the space-borne electromagnetic data that are neither related to magnetospheric signals and ionospheric plasma bubbles (see for instance Stolle et al., 2006) nor to main and lithospheric geomagnetic field anomalies but are likely of seismogenic origin. Additionally, complexity information measures like entropies (including non-extensive Tsallis entropy; Tsallis, 1988), natural time analysis ( see Varotsos et al., 2011 and references therein; Vallianatos et al., 2014) and fractal analysis (see for instance, Uritsky et al., 2004, Balasis et al., 2006, 2008, 2009, Eftaxias et al., 2009, 2010; Zhang et al., 2010; and the recent review by Balasis et al., 2013b) can be used to discriminate between normal and abnormal periods in the data, which can be related to quiescence and earthquake event epochs.

The above mentioned studies will be important in view of the recently launched ESA's Swarm mission. Swarm is a constellation of three satellites, providing precise simultaneous measurements of the magnetic field over different regions of the Earth (Olsen and Haagmans, 2006). Two of these 3 satellites are at a quite short distance, namely $150 \mathrm{~km}$, in a lower orbit. This fact will allow researchers to observe the small space-scale variations of the geomagnetic field, with particular attention to the lithospheric field. The past magnetic satellite missions were single satellite systems and so, before the launch of Swarm, we could observe just the large space-scale geomagnetic field. Swarm can, thus, offer a new, exciting and unique opportunity for distinguishing seismogenic emissions from non-seismic external (ionospheric and / or magnetospheric) electromagnetic signals, 
providing that proper analysis tools will be applied in order to extract the wealth of information that underlies the data.

\subsection{Neutral atmosphere}

The process of earthquake preparation is thought to be accompanied by some exchanges of mass and energy, which can change the energy budget in the earth-atmosphere system over the seismogenic zone. Many types of infrared physics parameters can be used to identify possible preearthquake anomalies. Brightness Temperature (BT), Outgoing Longwave Radiation (OLR), Surface Latent Heat Flux (SLHF), atmospheric temperature at different altitudes, could change before earthquakes and all these parameters are regularly recorded by satellite at regional and global scales. Examples of such variations of temperature or aerosols can be found in Pulinets et al. (2006), Jing et al. (2013), and Akhoondzadeh (2015). BT corresponds to the temperature of a black body that emits the same intensity as measured. OLR is the emission of the terrestrial radiation from the top of the earth's atmosphere to the space; it is controlled by the temperature of the earth and the atmosphere above it, in particular, by the water vapor and the clouds. SLHF describes the heat released by phase changes and depends on meteorological parameters such as surface temperature, relative humidity, wind speed, etcetera. If the detected IR anomaly is a real change of temperature or just an emission in the IR frequency band is debated. A recent paper (Piroddi et al., 2014) shows a clear thermal IR anomaly preceding the 2009 M6.2 L'Aquila (Italy) earthquake. The authors proposes a mechanism of generation of electric currents in the lithospheric rocks when they are under stress and a consequent IR irradiation with no actual temperature change (Freund et al., 2007; Freund, 2011). However, some recent works found SLHF (Qin et al., 2011) and surface temperature anomalies (Qin et al., 2012) before some large earthquakes, so supporting the possibility for some actual change of temperature too. Fig. 6 shows a comparison between skin temperature mostly deduced from satellite and ground temperature from a meteorological station for the 2012 Emilia 
earthquake (Qin et al., 2012): a thermal anomaly is seen also in the ground station, although its value is much less than the anomaly detected by the satellite.

Particular techniques must be applied to identify the anomalous signal in the thermal IR data. For instance, Tramutoli $(2007,2010)$ and Genzano et al. (2007, 2009) propose some Robust Satellite techniques that take into proper account the past behavior of the signal under investigation with the objective to recognize what is really an anomalous thermal deviation with respect to the typical seasonal and yearly background.

Recent interest was also addressed to air-quality data as possible indicators of an impending earthquake (e.g. Hsu et al., 2010). These authors found a staggering increase in ambient $\mathrm{SO}_{2}$ concentrations by more than one order of magnitude across the island several hours prior to two (M6.8 and M7.2) significant earthquakes in Taiwan.

An interesting although controversial study concerns the earthquake clouds, suggesting their formation because of some local weather conditions caused by energy and particle exchanges between crust and atmosphere that locally modify the global electric circuit during the earthquake preparation phase (e.g. Guangmeng and Jie, 2013; Harrison et al., 2014) or create the conditions for electrical discharges in an atmosphere that may be the source of very high frequency (VHF) radioemissions, sometime detected prior large earthquakes (Ruzhin and Nomicos, 2007). Due to the relevance of the role of the atmosphere in the lithosphere-ionosphere interaction, it is greatly important in the next future to systematically study atmospheric parameter variations in the context of earthquake forecast (e.g. Daneshvar et al., 2014). For example, air temperatures are available and can be quickly downloaded from the National Centers for Environmental Prediction (NCEP) Global reanalysis dataset, which is generated by assimilation with ground weather station and satellite data.

\section{Geospace anomalies by ground based observations}


The ionospheric anomalies can be registered up to one month in advance (middle - term precursors) as well as with lead times from some hours up to one day (short-term precursors) (Gufeld and Gusev, 1998; Vallianatos and Nomikos, 1998). Various parameters to detect the ionospheric anomalies can be monitored by ground based equipments such as ionosondes and GPS receivers: F2-layer critical frequency (foF2), Total Electron Content(TEC), electron temperature(Te), at F2layer heights, and LF radio signals (see e.g. Ondoh, 2009; Trigunait et al., 2004; Hobara and Parrot, 2005; Liu et al., 2006; Maekawa et al., 2006; Ondoh and Hayakawa, 2006; Dabas et al., 2007; Chmyrev et al., 2013).

The degree of reliability of the revealed associations is different in the diverse analyses. Hobara and Parrot (2005) analysed the foF2 variations recorded by the ionosonde stations in the Asian longitudinal sector to study the isolated and very powerful M8.3 Hachinohe earthquake occurred on 1968. The foF2 decrease was registered in the vicinity of the epicenter and not further than $1500 \mathrm{~km}$ apart: a pronounced ionospheric reaction to the event was detected. Liu et al. (2006) have analyzed the association between foF2 and 184 earthquakes with M5+ which took place during the period 1994-1999 in the Taiwan area. They observed a decrease in foF2 by $>25 \%$ within 5 days before the earthquakes. As expected, the effect increases with the earthquake magnitude but decreases with the distance from the epicenter to the ionospheric station: in practice, only the M5.4+ earthquakes and within the distance of $150 \mathrm{~km}$ have a significant chance to result in a pronounced foF2 decrease.

Also the sporadic E layer (Es) change was found interesting: its occurrence probability and the frequency (foEs) increase in the semi-transparency range have been considered by Silina et al. (2001). Ondoh and Hayakawa (2006) observed an anomalous foEs increase together with unusual ELF radio noises in the daytime on January 15, 1995 at Shigaraki and Kokubunji of epicentral distances within $500 \mathrm{Km}$ from the Hyogo-ken Nambu earthquake (M=7.2) occurred later in the same day. An analogous investigation has been carried out by searching for anomalous variations of Es and F2 layers parameters from Rome (Italy) ionosonde data occurring before Italian earthquakes ( 1979-2009) with magnitudes M ranged between 5.5 and 6 (Perrone et al., 2010). The results are 
similar to those obtained for the Japanese earthquakes but large lead times for the precursor occurrence (up to 34 days for $M=5.8-5.9$ ) tells about a longer preparation period.

On May $12^{\text {th }} 2008$, the devastating M8 Wenchuan earthquake struck the eastern edge of the Tibetan plateau, collapsing buildings and killing thousands people in major cities aligned along the western Sichuan basin in China. By means of a network of 58 ground-based GPS receivers in China and nearby, Zhao et al. (2008) estimated the Total Electron Content (TEC). On one hand, Fig. 7 (left) shows that, on 3 May the ionosphere was disturbed at a global scale because of a geomagnetic storm during the period 00:00-10:00 UT, so the large enhancement in TEC around the East Asian region was not actually associated with the earthquake. On the other hand, Fig. 7 (right) shows the case of May $9^{\text {th }}$, i.e. 3 days prior to the main shock: the anomalous enhancement over southern China is now likely a seismic precursor because there was no magnetic activity. The presence of its conjugate point in the southern hemisphere, confirms a characteristics trait of an ionospheric coupled to VAB phenomenology (Zhao et al., 2008).

To be complete with experimental devices to survey the ionosphere one should mention the topside ionospheric sounders embarked onboard satellites which were used by Pulinets (1998) and Pulinets and Legen'ka (2003) to detect density perturbations before earthquakes.

Another ionospheric indicator has been recently considered in looking for ionospherelithosphere coupling. The ionosphere may exhibit plasma irregularities of different sizes. The effects of these irregularities on the propagation of radio waves may be treated by diffraction and refraction theory. As a wave travels through a heterogeneous and anisotropic medium, it will accumulate changes of amplitude and phase, the so called ionospheric scintillations (e.g. Spogli et al., 2013). Some preliminary results (e.g. Kandalyan and Alquran, 2010) indicate that the correlation between the occurrence of strong earthquakes and ionospheric scintillation is worth being investigated.

The above results highlight that proper data selection and caution are needed to better discriminate between real seismo-ionospheric anomalies, outer space causes, and even artifacts (He et al., 2014) 
revealing that sometime the coversphere (vegetation, soil state and composition, etc.) could contrast the lithosphere-atmosphere-ionosphere coupling.

\subsection{Geomagnetic field}

The Information Theory (Shannon, 1948) can be applied with success to satellite geomagnetic data for extracting eventual anomalies. This technique has high time-space resolution using a preliminary wavelet analysis (e.g. see Balasis and Mandea, 2007 for wavelets applied to satellite geomagnetic data) in order to detect shorter-wavelength anomalies. Cianchini et al. (2009) computed the wavelet entropy content of CHAMP satellite magnetic data, taken over periods including the times of two large earthquakes occurred in the Sumatra region, revealing an anomalous period some minutes before the largest earthquake occurrence.

More recently, Cianchini et al. (2012) have analysed the components of the geomagnetic field variations, measured at the ground based magnetic observatory of L'Aquila (Central Italy), introducing the Transfer Function Entropy. This approach allowed these authors to detect specific anomalous periods in the magnetic data: this analysis pointed out clear temporal burst regimes of a few distinct harmonics corresponding to lower crust skin depths and preceding the main shock of the seismic sequence. The results obtained by means of other more conventional techniques applied to magnetic observatory data have been strongly criticized (e.g. Masci and Di Persio, 2012).

\subsection{Integration with ground seismic data}

Earthquakes can be in principle considered as elements of a statistical point process. Thus all tools of analysis for this kind of process are worth applying to time/space distributions of earthquakes. An empirical law is well known in seismology: the Gutenberg-Richter law (Gutenberg and Richter, 1944). It provides a statistical frame to represent all earthquakes occurred in given area (or even worldwide) and time as a simple log-linear function relating the number $N$ of earthquakes with 
magnitude equal to or greater than $M$, and the magnitude itself: $\log N=a-b M$, where $a$ and $b$ are two constant region-dependent parameters, although usually $b \approx 1$. It has always been recognized the importance of the $b$-value for understanding the state of stress in a certain seismic area. Recently De Santis et al. (2011) have shown that the $b$-value is directly connected with the Shannon entropy of earthquakes. Seismic entropy aims at characterizing the past and present seismicity, extracted from the Catalogs, affecting a seismogenic area and is a central concept of Geosystemics (De Santis, 2009, 2014).

Interesting results have been obtained by the use of the so-called Accelerated Moment Release (AMR) approach (Bufe and Varnes, 1993) that consists in fitting the cumulative value of a specific quantity related to the magnitude of each foreshock, e.g. the scalar Benioff strain, $s(t)$, with a power law in the time to failure $t_{f}$, i.e. the theoretic time of occurrence of the sequence main shock (e.g. Papazachos and Papazachos, 2001; Tzanis and Vallianatos, 2003; De Santis et al., 2010; and a recent review by Mignan, 2011): $s(\mathrm{t})=A+B\left(t_{f}-t\right)^{m}$, where $A, B$ and $m$ are appropriate empirical constants. The fitting process gives as an outcome the time $t_{f}$ together with the expected magnitude, which is related to either $A$ or $B$. Although this approach has been strongly criticized (Hardebeck et al., 2008), De Santis et al. (2010) applied it to the 2009 L'Aquila (Central Italy) seismic sequence as a means to highlight its intrinsic chaotic features. In practice, the fitting process is performed dayby-day and the results obtained are investigated for their behavior in time. A stable outcome in time of the different parameters can be a reliable indication for an impending earthquake (De Santis et al., 2010). Sometime AMR can been considered in combination with a seismic deceleration that occurs almost in the same area, resulting in a more robust identification of the impending earthquake epicenter (Papazachos et al., 2010).

Very recently, in order to overcome most of the criticisms by Hardebeck et al. (2008), De Santis et al. (2015) modified the expression of the Benioff strain, including an attenuation factor, in order to take into account the different effect of each earthquake to the impending sliding fault according to 
the distance, verifying the method both for real seismic sequences in Italy and comparing these results with shuffled simulated series of earthquakes.

A systematic research in the worldwide seismic catalogs (e.g. Kagan, 1996; Kossobokov et al. 1999; Zöller et al., 2002; Kossobokov 2014), together with simultaneous remote sensing analysis over the same area, would disclose the local to regional nonlinear characteristics of the seismic sequences in order to better understand the earthquake phenomenon from the classic to the new geosystemics point of view.

\section{Anthropogenic, atmospheric and outer-space effects}

Most of the geospace anomalies are not of lithospheric origin, they are rather due to human activities, or induced by the atmosphere, or can originate from the outer space. Below we describe them with some detail. Their identification are important to exclude possible false earthquakerelated precursors.

\subsection{Perturbations from Power Lines}

PLHR's (Power Line Harmonic Radiation) are the ELF and VLF waves emitted by the power lines at the harmonics of $50 \mathrm{~Hz}$ (or $60 \mathrm{~Hz}$ in USA). But these lines are not alone to radiate harmonics. Direct observations of PLHR by satellites are rather rare (Parrot, 1995) and shown in few papers (indirect effects are more often reported). Non linear interactions between electrons and PLHR can participate in the precipitation of electrons from the slot region in the radiation belts, on the other hand, main part of the PLHR energy dissipates in the lower ionosphere and modifies the ionospheric currents. This problem now requires serious attention because the electrical power consumption is always increasing in the world.

A systematic research on PLHR's has been performed using all burst DEMETER data. From VLF spectrograms, it is easy to find at the satellite altitude, the spectral lines separated by $50 \mathrm{~Hz}$ in 
Europe and by $60 \mathrm{~Hz}$ in USA (Němec et al., 2007 and references therein). Examples of PLHR's have been published by Parrot and Němec (2009) and the Fig. 8 shows one of these events.

\subsection{Perturbations from VLF Transmitters}

At VLF frequencies between 10 and $20 \mathrm{kHz}$, the ground based transmitters are used for radio navigation and communications. Their ionospheric perturbations include: the triggering of new waves, ionospheric heating, wave electron interactions, and particle precipitation. At HF frequencies, the broadcasting stations utilize powerful transmitters which can heat the ionosphere and change the temperature and the density. All these wave dissipations in the ionosphere could participate to the global warming of the Earth because the change in global temperature increases the number of natural lightning discharges in the atmosphere. Then the supplementary lightning discharges produce more magnetospheric whistlers which, in turn, could produce heating and ionization in the lower ionosphere.

The ground-based VLF transmitters are mainly used for communications by the army. They emit at fixed frequencies and their waves are propagated and bouncing in the Earth-ionosphere waveguide. But the ionosphere is not regular and these waves can also cross the ionosphere and be observed by a satellite. DEMETER has shown that the most powerful transmitter NWC in Australia can perturb and heat the ionosphere on a vast scale. The Fig. 9 shows an example of these ionospheric modifications which are observed at the satellite altitude. The waves, which cross the ionosphere and propagate in the opposite hemisphere, can also perturb the particles of the radiation belts due to wave-particle interaction as it has been studied by Sauvaud et al. (2008).

Furthermore, there is a potential feedback mechanism because two different processes could be involved. First, lightning is a source of NOx, and NOx affects the concentration of ozone in the atmosphere which contributes to the greenhouse effect. Second, precipitation of energetic electrons 
by man-made waves may trigger other lightning discharges. It explains the importance of the study of such man-made waves (Parrot and Zaslavski, 1996).

It must be also noted that anomalous propagation of the navigation VLF transmitters' signals has been detected before the occurrence of earthquakes when the epicenter is located between the transmitter and the receiver (see for example, Molchanov et al. 2006 and Rozhnoi et al., 2009), as well as unexpected anomalous pre-seismic transmission resulted in VHF radio waves (Fujiwara et al., 2004; Moriya et al., 2010).

\subsection{Ionospheric perturbations driven by the outer space}

The ionospheric perturbations from above are due to other sources, such as solar activity, acoustic gravity waves, travelling ionospheric disturbances, plasma dynamics, and large meteorological phenomena. In particular the solar activity induces magnetic storms. On these occasions, a flow of particles (energetic electrons and ions) forming the so called solar wind is injected in the nearEarth's environment affecting the state of the ionosphere-atmosphere system.

At the beginning of the DEMETER satellite mission, the solar activity cycle was just at the start of its decreasing phase and the satellite has suffered very intense magnetic storms which allowed to reveal new phenomena which were not observed before. The Figure 10 shows an example of plasma bubbles close to the equator.

One must also pay attention to the plasma dynamics. In the equatorial and low mid-latitude ionospheric regions, the distribution of plasma is controlled by the coupled processes of plasma diffusion, ExB drifts, thermospheric neutral winds, and chemical processes. The daytime (nighttime) F region plasma is transported by a vertical upward (downward) $\boldsymbol{E} \times \boldsymbol{B}$ drift, created by interaction between the ionospheric $\boldsymbol{E}$ field and the geomagnetic $\boldsymbol{B}$ field, over the dip equator, and by field-aligned diffusions on both sides of the dip equator. This is commonly known as the Equatorial Ionospheric Anomaly (EIA). 
These processes have a tendency to create a plasma distribution symmetric to the dip equator and local TEC gradients. As already stated, if TEC gradients are present, a trans-ionospheric signal propagating through them could encounter distortion of the original wave front, giving rise to a randomly modulated wave, i.e. the ionospheric scintillation. If received by specially modified GNSS multi-frequency multi-constellation receivers at ground, we are able to measure the ionospheric scintillation parameters associated with the TEC gradients.

During the equinoctial and summer months, the ionospheric scintillation induced by EIA is a daily phenomenon in the equatorial regions. It occurs mainly in the local post sunset hours (Spogli et al., 2013 and references therein) and must be taken into account when investigating ionospheric/inner magnetospheric perturbations coming from below.

Fig. 11 reports the ionospheric scenario over Brazil due to the EIA derived from a GNSS network in Brazil (CIGALA/CALIBRA projects, funded by EC-FP7): on the left, the occurrence of moderate/strong amplitude scintillation (S4 index) is mapped, while on the right the corresponding standard deviation of the TEC rate of change with respect to time (ROT) is shown (Spogli et al., 2013).

At high latitude, the formation of scintillation-driving irregularities can result from patches of plasma density the steep edges of which are unstable, so that smaller scale density structures develop along these edges. Within the auroral oval and cusp, precipitating energetic particles produce enhanced electron densities in correspondence of the auroral oval boundaries. Within the polar cap, ionospheric irregularities are associated with patches, as discrete electron density enhancements in the F layer.

The features of the scintillation patterns at high latitude is mostly characterized by the interplay between the interplanetary magnetic field (IMF) and the geomagnetic field. As an example, figure 12 shows the occurrence of moderate/strong phase scintillation above European high latitude region along year 2008 (low solar activity) as a function of the magnetic latitude and magnetic local time. Top plot is for IMF Bz positive conditions, while bottom plot is for negative conditions. Black and 
red curves reproduce the modeled auroral ovals (Feldstein model) for quiet $(\mathrm{IQ}=0)$ and moderately disturbed (IQ=3) geomagnetic conditions, respectively (extracted from Alfonsi et al., 2011). This shows how the orientation of the IMF influences the scintillation patterns in magnetic local time, highlighting the important role of the plasma inflow and outflow from and to the magnetosphere in the noon and midnight hours. Thus, also when high latitudes ionospheric data are considered, scintillation effects could mask other signatures of main interest (as the ones eventually due to lithosphere coupling) and should be removed.

\subsection{Perturbations from the atmosphere}

Atmospheric perturbations, such as thunderstorms, lightning, polar auroras, etc., are known to produce large electric fields, wave (whistler) production and particle acceleration (e.g. MacGorman and Rust, 1998). Our interest in wave/particle production and acceleration in the atmosphere is connected with the study of the physical processes producing high-energy phenomena. From this point of view, gamma-ray production and particle acceleration by waves are all interconnected.

An outstanding issue is the assessment of the possible correlation between wave/particle phenomena detected in the ionosphere/inner magnetosphere with large atmospheric storms and thunderstorms/lightning.

DEMETER satellite registered the electromagnetic emissions induced by the atmospheric lightning strokes and thunderstorm in all frequency ranges (Parrot et al., 2008a, Parrot et al., 2008b).

An example of particle perturbations is given in Fig. 13, which shows the simultaneous comparison of VLF spectrograms with the data of the particle detector IDP as measured by DEMETER. This allowed to reveal the precipitation of the particles in the radiation belts induced by the waves emitted by the lightning stroke which are propagated along the magnetic field lines from one hemisphere to another (Inan et al., 2007). 
Recently, Parrot et al. (2013) have shown that intense thunderstorm activity (where transient luminous events are often associated) can perturb the ionospheric density as illustrated in Fig. 14.

\section{Discussion}

A general approach to the problem of identifying an ensemble of temporal quasi-synchronous and spatial organised anomalies, possibly associated with an impending earthquake, should be multiparametric and multi-sensor, and the investigation must be multi-disciplinary.

Based on data for selected events from earthquake catalogues (time, geographical position, depth, magnitude, eventually also focal mechanism), geophysical parameters (e.g. ionospheric density, electron temperature, e.m. fields, TEC, scintillation, etc) from LEO satellites (e.g. DEMETER, CHAMP, Swarm) and ground based observations should be systematically analysed in order to detect anomalous variations. Different time intervals, e.g of about 45 days before the earthquake time and at least one week after, should be also considered to investigate different steps of the earthquake preparation phase. In all cases, even for single case study, data of the same period of time in previous years need to be considered, in order to evaluate some statistics to assess if special conditions are at play during the earthquake preparation phase (see, e.g., Qin et al., 2012) . The analysis can be statistical or (almost) deterministic (i.e. case study oriented). The former requires to see how many earthquakes are preceded by the geospace anomalies (and vice versa) under investigation and which is the eventual time in advance (e.g. Němec et al., 2008; Píša et al., 2012): this kind of study aims at establishing the degree of confidence about the presence of a significant statistical correlation between lithospheric and ionospheric events. The latter focuses on some specific case studies, especially for large earthquakes to establish if the geospace anomaly is unequivocally of lithospheric origin (e.g. Píša et al., 2011; He et al., 2014): this latter kind of study aims at identifying the most appropriate model of lithosphere-atmosphere-ionosphere coupling. 
In addition, the use of the high-energy particle data collected by satellites (e.g. NOAA satellites, AGILE) will allow a deeper investigation on possible enhancements of activity (particle bursts, flux increases) geomagnetically related with lithospheric events.

As stated in section 4, the impact of phenomena of anthropogenic, atmospheric and outer-space origin should be seriously taken into account when searching for the lithospheric signatures in the geospace. A best practice to remove (or avoid) outer-space contribution in the ground based as well satellite data is a proper data selection, based on periods with low geomagnetic indices (the most useful are $K p$ and $D s t$ ) and at particular local time, so removing most of the aperiodic and periodic magnetic variation of external origin. When considering the data selection, it is necessary to take into account also the characteristics of the region under study such as, for example the magnetic latitude. Climatology of scintillation over a specific area indicating where and when ionospheric perturbations are more likely to occur, man-made sources of disturbances, period of solar and magnetic storms, thunderstorms should be taken into account in discussing the analysis results if they impact in the lithospheric phenomena under investigation.

Once the multi-parametric/sensor/disciplinary analysis results will be assessed, efforts should be addressed in modelling the lithosphere-atmosphere-ionosphere coupling in order to improve the knowledge on the earthquake cause-effect.

There are many theories that attempt to describe the physical processes manifesting some anomalous behaviour in some parameters before earthquakes and try to explain why these precursors may occur. A review of these processes can be found in Pulinets and Boyarchuk (2004), Freund (2011), Pulinets and Ouzounov (2011) and the references therein. A process that can explain many observations is based on the emission of a radioactive gas or metallic ions before an earthquake, which may change the distribution of electric potential above the surface of the Earth and then up to the ionosphere (e.g., Sorokin et al., 2001), and would also explain the thermal earthquake-related anomalies (Tramutoli et al., 2013). Penetration of the electric field to the 
ionosphere could induce anomalies in the ionospheric plasma density and/or conductivity, which are observed above seismic zones (see e.g., Liu et al., 2006; Kon et al., 2011). Harrison et al. (2010) proposed that radon emitted before an earthquake would increase the conductivity of air at ground level and that the ensuing increase of current in the fair weather global circuit would lower the ionosphere. However, Freund et al. (2009) have estimated that even if radon is coming out the ground in seismic areas, its contribution to the air conductivity is of minor importance relative to the air ionization rate which can be expected from charge carriers from the rocks, the so-called positive-holes (or p-holes). They have shown experimentally that these mobile electric charge carriers flow out of the stressed rocks (see Freund et al., 2009, and references therein): at the Earth's surface, they cause extra ionization of the air molecules. However, the original experiments that detected these p-holes, have been recently contrasted (Dahlgren et al., 2014). We cannot be exhaustive here about the extensive works on electrical phenomena detected in rocks, but we mention only some of the most recent ones such as Vallianatos and Triantis (2008) and Vallianatos et al. (2012).

Kuo et al. $(2011,2014)$ have shown that ionospheric density variations can be induced by changes of the current in the global electric circuit between the bottom of the ionosphere and the Earth's surface where electric charges associated with stressed rocks can appear. The interaction of the anomalous electric current with the geomagnetic field can even amplify the effect in the higher atmosphere (Kuo et al., 2014).

Enomoto (2012) introduces a fault model that takes account of the couple interaction between earthquake nucleation and deep Earth gases, and proposes a physical model of magnetic induction coupling with ionosphere before large offshore earthquakes.

As a further effect of an earthquake, it is also known that just after the occurrence of a sufficiently large event the possibility of observing the effect of the propagation of acoustic gravity waves in the ionosphere exists. 


\section{Conclusions and future directions}

There is no well established model of the lithosphere-atmosphere-ionosphere coupling (e.g. Pulinets and Boyarchuk 2004, Liperovsky et al. 2008, Freund 2011). The main research of scientists working on it will be dedicated to find a final answer. To do that, they will investigate space-borne data from a series of low-Earth orbit (LEO) European satellites, as the recently launched Swarm constellation (Olsen and Haagmans, 2006) and the past CHAMP and DEMETER missions, along with an ongoing magnetospheric mission (ESA's Cluster four multi-spacecraft 2000-to date mission) in order to detect and identify possible signatures in magnetometer, electric field and particle detector recordings on-board these satellites of electromagnetic perturbations related to earthquakes. These perturbations can be pre-, co- or post-seismic signals and will constitute an ensemble of sequentially time ordered, spatially organised and physically related anomalies, and their correlations with seismic cycles will be assessed. The emphasis must be put on the analysis of the measurements from the three topside ionosphere missions and Cluster can be used to separate from signals originated in the magnetosphere. Ground data from seismic and geomagnetic stations, together with ionosondes, nearby a corresponding earthquake epicenter can be used, whenever a nearby ground station exists, in order to compare them with the satellite observations. The rich datasets of CHAMP (2000-2010) and DEMETER (2004-2010) can be used for statistical analyses of past earthquake events, while Swarm constellation of three satellites will serve for the study of seismic events after its launch (22 November 2013), as well as the next satellite CSES (Chinese Seismo-Electromagnetic Satellite), specifically designed for finding e.m. signatures related to earthquakes (Shen et al., 2011) and to be launched in 2016. Thermal IR data from other satellites (e.g. ESA Sentinel missions, EUMETSAT consortium satellites etc.) will provide an integrated dataset to be included in any interdisciplinary study of lithosphere-atmosphere-ionosphere coupling in the search of the best physical model explaining the available ground and satellite based observations. 


\section{Acknowledgements}

The idea to prepare this paper was born during the active collaborations among most of the coauthors in the framework of the preparation of a proposing project to Horizon 2020. Q.E. and P.-C. F.C. received an INGV Fellowship under the SAGA-4-EPR project funded by the Italian Foreign Office after an Italian-Chinese bilateral Governmental Agreement. GB acknowledges additional support from the European Union Seventh Framework Programme (FP7-REGPOT-2012-2013-1) under grant agreement no. 316210 (BEYOND - Building Capacity for a Centre of Excellence for EO-based monitoring of Natural Disasters). The final phase of the work was made under the project SAFE (Swarm For Earthquake study) funded by ESA. 


\section{References}

Akhoondzadeh, M., 2015. Ant Colony Optimization detects anomalous aerosol variations associated with the Chile earthquake of 27 February 2010, Adv. Space Res., 55, 1754-1763.

Aleksandrin, S.Yu., Galper, A.M., Grishantzeva, L.A., Koldashov, S.V., Maslennikov, L.V., Murashov, A.M., Picozza, P., Sgrigna, V., Voronov, S.A., 2003. High-energy charged particle bursts in the near-Earth space as earthquake precursors Annales Geophysicae, 21, 597-602.

Alfonsi, L., Spogli, L., De Franceschi, G., Romano, V., Aquino, M., Dodson, A., Mitchell, C.N., 2011. Bipolar climatology of GPS ionospheric scintillation at solar minimum. Radio Science, 46(3).

Balasis G., Daglis, I.A., Kapiris, P., Mandea, M., Vassiliadis, D., Eftaxias, K., 2006. From prestorm activity to magnetic storms: a transition described in terms of fractal dynamics, Annales Geophysicae, 24, 3557-3567.

Balasis, G., Mandea, M., 2007. Can electromagnetic disturbances related to the recent great earthquakes be detected by satellite magnetometers?, Tectonophysics, 431, 173-195.

Balasis, G., Daglis, I.A., Papadimitriou, C., Kalimeri, M., Anastasiadis, A., Eftaxias, K., 2008. Dynamical complexity in Dst time series using nonextensive Tsallis entropy, Geophys. Res. Lett., 35, L14102, doi:10.1029/2008GL034743.

Balasis, G., Daglis, I.A., Papadimitriou, C., Kalimeri, M., Anastasiadis, A., Eftaxias, K., 2009. Investigating dynamical complexity in the magnetosphere using various entropy measures, $\mathrm{J}$. Geophys. Res., 114, A00D06, doi:10.1029/2008JA014035.

Balasis, G., Daglis, I.A., Zesta, E., Papadimitriou, C., Georgiou, M., Haagmans, R., Tsinganos, K., 2012. ULF wave activity during the 2003 Halloween superstorm: multipoint observations from CHAMP, Cluster and Geotail missions, Ann. Geophys., 30, 1751-1768, doi:10.5194/angeo-301751-2012. 
Balasis, G., Daglis, I.A., Georgiou, M., Papadimitriou, C., Haagmans, R., 2013a. Magnetospheric ULF wave studies in the frame of Swarm mission: a time-frequency analysis tool for automated detection of pulsations in magnetic and electric field observations, Earth, Planets and Space, 65, $1385-1398$.

Balasis, G., Donner, R.V., Potirakis, S.M., Runge, J., Papadimitriou, C., Daglis, I.A., Eftaxias, K., Kurths, J., 2013b. Statistical mechanics and information theoretic perspectives on complexity in the Earth system, Entropy, 15 (11), 4844-4888; doi:10.3390/e15114844.

Battiston R., Vitale V., 2013. First evidence for correlations between electron fluxes measured by NOAA-POES satellites and large seismic events, Nuclear Physics B (Proc. Suppl.) 243, 249_ 257.

Berthelier, J.-J., Malingre, M., Pfaff, R., Seran, E., Pottelette, R., Jasperse, J., Lebreton, J.-P., Parrot, M., 2008. Lightning-induced plasma turbulence and ion heating in equatorial ionospheric depletions, Nature Geoscience, 1, 101-105.

Briggs, M. S., et al., 2013. Terrestrial gamma-ray flashes in the Fermi era: Improved observations and analysis methods, J. Geophys. Res., 118, 3805-3830.

Bufe, C.G., Varnes, D.J., 1993. Predictive modeling of the seismic cycle of the Greater San Francisco Bay region. J. Geophys. Res. 98, 9871-9883.

Campbell W. H.; 2009: Natural magnetic disturbance fields, not precursors, preceding the Loma Prieta earthquake, J. Geophys. Res., 114, A05307, doi:10.1029/2008JA013932.

Chmyrev, V., A. Smith, D. Kataria, B. Nesterov, C. Owen, P. Sammonds, V. Sorokin, F. Vallianatos, 2013. Detection and monitoring of earthquake precursors: TwinSat, a Russia-UK satellite project, Advances in Space Research , 52, 6, 1135-1145.

Cianchini, G., De Santis, A., Balasis, G., Mandea, M., Qamili, E., 2009. Entropy based analysis of satellite magnetic data for searching possible e.m. signatures due to big earthquakes, Proceedings of WSEAS International Conference on GEOLOGY and SEISMOLOGY GES '09, Feb. 2009 Cambridge, 29-35. 
Cianchini, G., De Santis, A., Barraclough, D.R., Wu, L.X., Qin, K., 2012. Magnetic transfer function entropy and the $2009 \mathrm{Mw}=6.3$ L'Aquila earthquake (Central Italy), Nonlin. Processes Geophys., 19, 401-409.

Cicerone, R.D., Ebel, J.E., Britton, J., 2009. A systematic compilation of earthquake precursors, Tectonophysics, 476, 371-396.

Dabas, R.S., Das, R.M., Sharma, K., Pillai, K.G.M., 2007. Ionospheric precursors obseryed over low latitudes during some of the recent major earthquakes, J. Atmos. Solar-Terr. Phys., 69, $1813-1824$.

Dahlgren, P. R., M. J. S. Johnston, V. C. Vanderbilt, and R. N. Nakaba, 2014. Comparison of the stress-stimulated current of dry and fluid saturated gabbro samples, Bulletin of the Seismological Society of America, 104, 2662-2672.

Daneshvar M. R. M., T. Tavousi , M. Khosravi, 2014. Synoptic detection of the short-term atmospheric precursors prior to a major earthquake in the Middle East, North Saravan M 7.8 earthquake, SE Iran, Air Qual Atmos Health, 7, 29-39.

De Santis, A., 2009. Geosystemics. Proceedings of WSEAS International Conference on Geology and Seismology GES '09, Feb. 2009 Cambridge, 36-40.

De Santis, A., 2014. Geosystemics, entropy and criticality of earthquakes: a vision of our planet and a key of access, in "Nonlinear phenomena in Complex Systems: from Nano to Macro Scale" ed. E. Stanley and D. Matrasulov, NATO Science for Peace and Security Series - C: Environmental Security.

De Santis, A., Cianchini, G., Qamili, E., Frepoli, A., 2010. The 2009 L'Aquila (Central Italy) seismic sequence as a chaotic process, Tectonophysics, 496, 44-52.

De Santis, A., Cianchini, G., Favali, P., Beranzoli, L., Boschi, E., 2011. The Gutenberg-Richter law and Entropy of earthquakes: two case studies in Central Italy, Bull. Seism. Soc. Am., 101, No.3, 1386-1395. 
De Santis, A., Cianchini G., Di Giovambattista, 2015. Accelerating moment release revisited: examples of application to Italian seismic sequences, Tectonophysics, 639, 82-98.

Dobrovolsky, I.R., Zubkov, S.I., Myachkin, V.I., 1979. Estimation of the size of earthquake preparation zones, Pageoph., $1025-1044$.

Eftaxias, K., Athanasopoulou, L., Balasis, G., Kalimeri, M., Nikolopoulos, S., Contoyiannis, Y., Kopanas, J., Antonopoulos, G., Nomicos, C., 2009. Unfolding the procedure of characterizing recorded ultra low frequency, $\mathrm{kHZ}$ and $\mathrm{MHz}$ electromagnetic anomalies prior to the L'Aquila earthquake as preseismic ones - Part 1, Nat. Hazards Earth Syst. Sci., 9, 1953-1971.

Eftaxias, K., Balasis, G., Contoyiannis, Y., Papadimitriou, C., Kalimeri, M., Athanasopoulou, L., Nikolopoulos, S., Kopanas, J., Antonopoulos, G., Nomicos, C., 2010. Unfolding the procedure of characterizing recorded ultra low frequency, $\mathrm{kHZ}$ and $\mathrm{MHz}$ electromagnetic anomalies prior to the L'Aquila earthquake as pre-seismic ones - Part 2, Nat. Hazards Earth Syst. Sci., 10, 275294.

Enomoto, Y., 2012. Coupled interaction of earthquake nucleation with deep Earth gases: a possible mechanism for seismo-electromagnetic phenomena, Geoph. Journ. Inter., 191, 1210-1214.

Fidani, C., Battiston, R., 2008. NOAA particle data and correlations to seismic activity. Nat. Haz. Earth Syst. Sci., 8, 1277-1291.

Fiser, J., Chum, J., Diendorfer, G., Parrot, M., Santolik, O., 2010. Whistler intensities above thunderstorms, Ann. Geophys., 28, 37-46.

Fraser-Smith A. C., Bernardi A., McGill P. R., Ladd M.E., Helliwel R.A and Villard O.G. Jr.; 1990. Low frequency magnetic field measurements near the epicenter of the Loma-Prieta earthquake, Geophys. Res. Lett., 17, 9, 1465-1468, doi:10.1029/GL017i009p01465.

Fraser-Smith A. C., McGill P. R. and Bernardi A.; 2011. Comment on "Natural magnetic disturbance fields, not precursors, preceding the Loma Prieta earthquake" by Wallace H. Campbell, J. Geophys. Res., 116, A08228, doi:10.1029/2010JA016379 
Freund, F.T., 2011. Pre-earthquake signals: Underlying physical processes, J. of Asian Earth Sci., $41,383-400$.

Freund, F.T., Takeuchi, A., Lau, B.W.S., Al-Manaseer, A., Fu, C.C., Bryant, N.A., Ouzounov, D., 2007. Stimulated thermal IR emission from rocks: assessing a stress indicator, eEarth, 2, 1-10.

Freund, F.T., Kulahci, I.G., Cyr, G., Ling, J., Winnick, M., Tregloan-Reed, J., Freund, M.M., 2009. Air ionization at rock surfaces and pre-earthquake signals, J. Atmos. Sol. Terr. Phys., 71 (1718), 1824-1834, doi:10.1016/j.jastp.2009.07.013.

Fujiwara, H., M. Kamogawa, M. Ikeda, J.Y. Liu, H. Sakata, Y.I. Chen, H. Ofuruton, S. Muramatsu, Y.J. Chuo, and Y.H. Ohtsuki, 2004. Atmospheric anomalies observed during earthquake occurrences, Geoph. Res. Lett., vol.31, L17110, doi: 10.1029/2004GL019865.

Fuschino, F., et al., 2011. High spatial resolution correlation of AGILE TGFs and global lightning activity above the equatorial belt, Geophys. Res. Lett., 38, L14806.

Geller, R.J., Jackson, D.D., Kagan, Y.Y., Mulargia, F., 1997. Earthquakes Cannot Be Predicted, Science, 275, 1616-1618.

Genzano, N., Aliano, C., Filizzola, C., Pergola, N., \& Tramutoli, V. , 2007. Robust satellite technique for monitoring seismically active areas: The case of Bhuj-Gujarat earthquake. Tectonophysics, 431, 197-210.

Genzano, N., Aliano, C., Corrado, R., Filizzola, C., Lisi, M., Mazzeo, G., Paciello, R., Pergola, N., Tramutoli, V., 2009. RST analysis of MSG-SEVIRI TIR radiances at the time of the Abruzzo 6 April 2009 earthquake. Natural Hazards and Earth System Sciences, 9, 2073-2084.

Guangmeng, G., Jie, Y., 2013. Three attempts of earthquake prediction with satellite cloud images, Nat. Hazards Earth Syst. Sci., 13, 91-95.

Gufeld, I L., Gusev, G.A., 1998. Recent state of earthquake predictions (Is there any way out of the impasse?), in: Short-term prediction of catastrophic earthquakes using radar ground-space methods, edited by: Strakhov, V. N. and Liperovsky, V. A., Moscow , 7-25. 
Gutenberg, B., Richter, C.F., 1944. Frequency of earthquakes in California, Bull. Seism. Soc. Am., 34, 185-188.

Hardebeck, J.L., Felzer, K.R., Michael, A.J., 2008. Improved test results reveal that the accelerating moment release hypothesis is statistically insignificant, J. Geophys. Res., 113, B08310, doi:10.1029/2007JB005410.

Harrison, R.G., Aplin, K.L., Rycroft, M.J., 2010. Atmospheric electricity coupling between earthquake regions and the ionosphere, J. Atmos. Sol. Terr. Phys., 72, 376-381.

Harrison, R. G., K. L. Aplin, and M. J. Rycroft, 2014. Earthquake-cloud coupling through the global atmospheric electric circuit, Nat. Hazards Earth Syst. Sci., 14, 773-777.

Hayakawa, M., Molchanov, O.A. (Eds.), Seismo-Electromagnetics: Lithosphere-AtmosphereIonosphere Coupling. TERRAPUB, Tokyo.

He, L.M., Wu, L.X., De Santis, A., Liu S.J., Yang, Y., 2014. Is there a one-to-one correspondence between ionospheric anomalies and large earthquakes along Longmenshan faults?, Annales Geophysicae, 32, 187-196.

He, Y., Yang, D., Qian, J., and Parrot, M., 2011. Response of the ionospheric electron density to different types of seismic events, Nat. Hazards Earth Syst. Sci., 11, 2173-2180.

Hobara, Y., Parrot, M., 2005. Ionospheric perturbations linked to a very powerful seismic event, J. Atmos. Solar-Terr. Phys., 67, 677-685.

Hough, S., 2009. Predicting the Unpredictable: The Tumultuous Science of Earthquake Prediction. Princeton University Press.Hsu S.C., Y.T. Huang, Jr-Chung Huang, J.Y. Tu, G. Engling, C.Y. Lin, F.J. Lin, C.H. Huang, 2010. Evaluating real-time air-quality data as earthquake indicator, Science of the Total Environment, 408, 2299-2304.

Jing, F., Shen, X.H., Kang, C.L. and Xiong P., 2013. Variations of multi-parameter observations in atmosphere related to earthquake, Nat. Hazards Earth Syst. Sci., 13, 27-33. 
Inan, U.S., Piddyachiy, D., Peter, W.B., Sauvaud, J.A., Parrot, M., 2007. DEMETER satellite observations of lightning-induced electron precipitation, Geophys. Res. Lett., 34, L07103, doi:10.1029/2006GL029238.

Kagan D.D, 1996. Hypothesis testing and earthquake prediction, Proc. Natl. Acad. Sci. USA, Vol. $93,3772-3775$.

Kalimeri M., C. Papadimitriou, G. Balasis, and K. Eftaxias (2008), Dynamical complexity detection in pre-seismic emissions using nonadditive Tsallis entropy, Physica A 387, $1161-1172$.

Kamogawa M. , Pre-seismic Lithosphere-Atmosphere-Ionosphere Coupling, Eos, Vol. 87, No. 40, 3 October 2006.

Kandalyan, R.A., AlQuran, M.K., 2010. Ionosphere Scintillation and Earthquakes, Jourdan Journ. Phys., vol.3, No. 2, 69-76.

Kon, S., Nishihashi, M., Hattori, K., 2011. Ionospheric anomalies possibly associated with M_6.0 earthquakes in the Japan area during 1998-2010: Case studies and statistical study, J. Asian Earth Sci., 41, 410-420.

Kossobokov V.G., 2014. Times of increased probabilities for occurrence of catastrophic earthquakes: 25 years of hypothesis testing in real time, in Wyss (ed.) Earthquake Hazard, Risk and Disasters, Hazards and Disasters Series, Academic Press, London, pp. 478-504.

Kossobokov V.G., Romashkova L.L., Keilis-Borok V.I., Healy J.H., 1999. Testing earthquake prediction algorithms: statistically significant advance prediction of the largest earthquakes in the Circum-Pacific, 1992-1997, Phys. Earth Planet. Int., 111, 187-196.

Kuo, C.L., Huba, J.D., Joyce, G., Lee, L., 2011. Ionosphere plasma bubbles and density variations induced by pre-earthquake rock currents and associated surface charges, J. Geophys. Res., 116, A10317, doi:10.1029/2011JA016628.

Kuo, C.L., Lee, L., Huba, J.D., 2014. An improved coupling model for the lithosphere-atmosphereionosphere system, J. Geophys. Res., doi: 10.1002/2013JA019392. 
Larkina, V.I., Migulin V.V., Molchanov O.A., Kharkov I.P., Iuchin A.S., and Schvetcova V.B., 1989. Some statistical results on very low frequency radiowave emission in the upper ionosphere over earthquake zones, Phys. Earth Plan. Inter., 57 (1-2), 100-109.

Li, M. and Parrot, M., 2012. "Real time analysis" of the ion density measured by the satellite DEMETER in relation with the seismic activity, Nat. Hazards Earth Syst. Sci., 12, 2957-2963,

Li, M., and M. Parrot, 2013. Statistical analysis of an ionospheric parameter as a base for earthquake prediction, J. Geophys. Res. Space Physics, 118, 3731-3739.

Liperovsky, V.A., Pokhotelov, O.A., Meister, C.-V., Liperovskaya, E.V.,2008. Physical models of coupling in the lithosphere-atmosphere-ionosphere system before earthquakes, Geomagnetism and Aeronomy, 48, 6, 795-806.

Liu, J.Y., Chen, Y.I., Chuo, Y.J., Chen, C.S., 2006. A statistical investigation of pre-earthquake ionospheric anomaly, J. Geophys. Res., 111, A05304. doi:10.1029/2005JA011333.

Liu, J.Y., Tsai, Y.B., Chen, S.W., Lee, C.P., Chen, Y.C., Yen, H.Y., Chang, W.Y., Liu, C., 2006. Giant ionospheric disturbances excited by the M9.3 Sumatra earthquake of 26 December 2004, Geophys. Res. Lett., 33, doi:10.1029/2005GL023963.

MacGorman, D.R., Rust, W.D., 1998. The electrical nature of storms, Oxford University Press.

Maekawa, S., Horie, T., Yamauchi, T., Sawaya, T., Ishikawa, M., Hayakawa, M., Sasaki, H., 2006. A statistical study on the effect of earthquakes on the ionosphere, based on the subionospheric LF propagation data in Japan, Ann. Geophysicae, 24, 2219-2225.

Masci, F., Di Persio, M., 2012. Retrospective investigation of geomagnetic field time-series during the 2009 L'Aquila seismic sequence, Tectonophysics, 530-531, 310-317.

McCaffrey, R., 2011. Earthquakes and crustal deformation. In: Gupta, H.K. (Ed.), Encyclopedia of Solid Earth Geophysics. Springer, 218-226.

Mignan, A., 2011. Retrospective on the accelerating seismic release (AMR) hypothesis: controversy and new horizons. Tectonophysics 505, 1-16. 
Molchanov, O. A., E. Fedorov, A. Schekotov, E. Gordeev, V. Chebrov, et al., 2004. Lithosphereatmosphere-ionosphere coupling as governing mechanism for preseismic short-term events in atmosphere and ionosphere. Natural Hazards and Earth System Science, 4 (5/6), 757-767.

Molchanov, O., A. Rozhnoi, M. Solovieva, O. Akentieva, J. J. Berthelier, M. Parrot, F. Lefeuvre, P. F. Biagi, L. Castellana, and M. Hayakawa, 2006. Global diagnostics of the ionospheric perturbations related to the seismic activity using the VLF radio signals collected on the DEMETER satellite, Nat. Hazards Earth Syst. Sci., 6, 745-753.

Moriya, T., T. Mogi and M. Takada, 2010. Anomalous pre-seismic transmission of VHF-band radio waves resulting from large earthquakes, and its statistical relationship to magnitude of impending earthquakes, Geophys. J. Int., 180, 858-870.

Němec, F., Santolík, O., Parrot, M., Berthelier, J. J., 2007. Power line harmonic radiation: A systematic study using DEMETER spacecraft, Advances in Space Research, 40(3), 398-403.

Němec, F., Santolík, O., Parrot, M., Berthelier, J.J., 2008. Spacecraft observations of electromagnetic perturbations connected with seismic activity, Geophys.Res. Lett., 35, L05109, doi:10.1029/2007GL032517.

Olsen, N., Haagmans, R., (Guest Editors), 2006. Swarm- The Earth's Magnetic Field and Environmental Explorers, Special Issue, Earth Planets Space, 58, 349-496.

Ondoh, T., 2009. Investigation of precursory phenomena in the ionosphere, atmosphere and groundwater before large earthquakes of M > 6.5, Adv. Space Res., 43, 214-223.

Ondoh, T., Hayakawa, M., 2006. Synthetic study of precursory phenomena of the M7.2 Hyogo-ken Nanbu earthquake, Phys. Chem. Earth, 31, 378-388.

Papadimitriou, C., M. Kalimeri and K. Eftaxias, 2008. Nonextensivity and universality in the earthquake preparation process, Phys. Rev. E 77, 036101.

Papazachos, C., Papazachos, B., 2001. Precursory accelerated Benioff strain in the Aegean area. Ann. Geophys. 44, 461-474. 
Papazachos, B.C., Karakaisis, G.F., Scordilis, E.M., Papazachos, C.B., Panagiotopoulos, D.G., 2010. Present patterns of decelerating-accelerating seismic strain in South Japan. J. Seismol. 14, 273-288.

Parrot M. and Mogilevsky M.M., 1989. VLF emission associated with earthquakes and observed in the ionosphere and magnetosphere, Phys. Earth Plan. Inter., 57 (1-2), 86-99.

Parrot, M., 1995. Use of satellites to detect seismo-electromagnetic effects. Adv. Space Res., 15, $27-35$.

Parrot, M., Zaslavski, Y., 1996. Physical mechanisms of man-made influences on the magnetosphere. Surveys in Geophysics, 17(1), 67-100.

Parrot, M., Inan, U.S., Lehtinen, N., Blanc, E., Pinçon, J.L., 2008a. HF signatures of powerful lightning recorded on DEMETER, J. Geophys. Res., 113, A11321, doi:10.1029/2008JA013323.

Parrot, M., Inan, U.S., Lehtinen, N.G., 2008b. V-shaped VLF streaks recorded on DEMETER above powerful thunderstorms, J. Geophys. Res., 113, A10310, doi:10.1029/2008JA013336.

Parrot, M., Němec, F., 2009. MLR events and associated triggered emissions observed by DEMETER. Advances in Space Research, 44(9), 979-986.

Parrot, M., Sauvaud, J.A., Soula, S., Pinçon, J.L., van der Velde, O., 2013. Ionospheric density perturbations recorded by DEMETER above intense thunderstorms, J. Geophys. Res. Space Physics, 118, doi:10.1002/jgra.50460.

Perrone, L., Korsunova, L., Mikhailov, A., 2010. Ionospheric precursors for crustal earthquakes in Italy, Annales Geophysicae, 28, 941-950.

Piroddi, L., Ranieri, G., Freund, F., Trogu, A., 2014. Geology, tectonics and topography underlined by L’Aquila earthquake TIR precursors, Geophys. Journ. Int., 197, 1532-1536.

Píša, D., Němec, F., Parrot, M., Santolík, O., 2012. Attenuation of electromagnetic waves at the frequency $\sim 1.7 \mathrm{kHz}$ in the upper ionosphere observed by the DEMETER satellite in the vicinity of earthquakes, Annals of Geophysics, 55(1), 157-163. 
Píša, D., Němec, F., Santolik, O., Parrot, M., Rycroft, M., 2013. Additional attenuation of natural VLF electromagnetic waves observed by the DEMETER spacecraft resulting from preseismic activity, J. Geophys. Res. Space Physics, 118, doi:10.1002/jgra.50469.

Pulinets, S.A., Legen'ka, A.D., Alekseev, V.A., 1994. Pre-earthquakes effects and their possible mechanisms, in "Dusty and Dirty Plasmas, Noise and Chaos in Space and in the Laboratory". Plenum Publishing, New York. pp. 545-557.

Pulinets, S.A., Alekseev, V.A., Legen'ka, A.D., Khegai, V.V., 1997. Radon and metallic aerosols emanation before strong earthquakes and their role in atmosphere and ionosphere modification. Advances in Space Research 20, 2173-2176.

Pulinets, S.A., Khegai, V.V., Boyarchuk, K.A., Lomonosov, A.M., 1998. Atmospheric electric field as a source of ionospheric variability. Physics-Uspekhi 41, 515- 522.

Pulinets, S.A., Boyarchuk, K.A., Hegai, V.V., Kim, V.P., Lomonosov, A.M., 2000. Quasielectrostatic model of atmosphere-thermosphere-ionosphere coupling. Advances in Space Research 26, 1209-1218.

Pulinets S.A., 1998. Strong earthquakes prediction possibility with the help of topside sounding from satellites, Adv. Space Res., 21, 3, 455-458.

Pulinets S.A., Legen'ka A.D., 2003. Spatial-Temporal Characteristics of Large Scale Distributions of Electron Density Observed in the Ionospheric F-region before Strong Earthquakes, Cosmic Research, 41(3), 221-229.

Pulinets, S.A., Boyarchuk, K.A., 2004. Ionospheric Precursors of Earthquakes, Springer Verlag.

Pulinets, S.A. Ouzounov, D., 2011. Lithosphere-Atmosphere-Ionosphere Coupling (LAIC) model . An unified concept for earthquake precursors validation, J. Asian Earth Sci., 41, 371-382.

Pulinets S.A., Ouzounov D., Ciraolo L., Singh R., Cervone G., Leyva A., Dunajecka M., Karelin A.V., Boyarchuk K.A., Kotsarenko A., 2006. Thermal, atmospheric and ionospheric anomalies around the time of the Colima M7.8 earthquake of 21 January 2003, Annales Geophysicae, 24, 835-849. 
Qin, K., Wu, L.X., De Santis, A., Wang, H., 2011. Surface latent heat flux anomalies before the Ms 7.1 New Zealand earthquake 2010, Chinese Science Bulletin, 56, No 31, 3273-3280.

Qin, K., Wu, L.X., De Santis, A., Cianchini, G., 2012. Preliminary analysis of surface temperature anomalies that preceded the two major Emilia 2012 earthquakes (Italy), Annals of Geophysics, $55,4,823-828$.

Rodger, C.J., Clilverd, M.A., McCormick, R.J., 2003. Significance of lightning-generated whistlers to inner radiation belt electron lifetimes, J. Geophys. Res., 108(A12), 1462, doi:10.1029/2003JA009906.

Rozhnoi, A., Solovieva, M., Molchanov, O., Schwingenschuh, K., Boudjada, M., Biagi, P.F., Maggipinto, T., Castellana, L., Ermini, A., Hayakawa, M., 2009. Anomalies in VLF radio signals prior the Abruzzo earthquake (M=6.3) on 6 April 2009, Nat. Hazards Earth Syst. Sci., 9, $1727-1732$.

Ruzhin, Y., C. Nomicos, 2007. Radio VHF precursors of earthquakes, Nat. Hazard, 40, 573-583.

Saradjian, M.R., Akhoondzadeh, M., 2011. Prediction of the date, magnitude and affected area of impending strong earthquakes using integration of multi precursors earthquake parameters, Nat. Haz. Earth Syst. Sci., 11, 1109-1119.

Sauvaud, J.A., Maggiolo, R., Jacquey, C., Parrot, M., Berthelier, J. J., Gamble, R. J., Rodger, C. J., 2008. Radiation belt electron precipitation due to VLF transmitters: Satellite observations. Geophysical Research Letters, 35(9).

Sgrigna, V., Carota, L., Conti, L., Corsi, M., Galper, A.M., Koldashov, S.V., Murashov, A.M., Picozza, P., Scrimaglio, R., Stagni, L., 2005. Correlations between earthquakes and anomalous particle bursts from SAMPEX/PET satellite observations. J. Atmos. Sol.-Terr. Phys. 67, 14481462.

Shannon, C. E., 1948. A mathematical theory of communication, Bell Syst. Tech. J. 27, 379, 623. 
Shprits, Y., Subbotin, D., Drozdov, A., Usanova, M., Kellerman, A., Orlova, K., Baker, D., Turner, D., Kim, K., 2013. Unusual stable trapping of the ultrarelativistic electrons in the Van Allen radiation belts. Nature Physics 9, 99-703 doi:10.1038/nphys2760.

Shen, X., Zhang, X., Wang, L., Chen, H., Wu, Y., Yuan, S., Shen, J., Zhao, S., Qian, J. Ding, J., 2011. - The earthquake-related disturbances in ionosphere and project of the first China seismoelectromagnetic satellite, Earthq. Science, 24, 639-650.

Silina, A.S., Liperovskaya, E.V., Liperovsky, V.A., Meister, C.V., 2001. Ionospheric phenomena before strong earthquakes, Natural Hazards and Earth System Sciences, 1, 113-118.

Sorokin, V.M., Chmyrev, V.M., Yaschenko, A.K., 2001. Electrodynamic model of the lower atmosphere and the ionosphere coupling, J. Atmos. Sol. Terr. Phys., 63, 1681-1691.

Spogli, L., Alfonsi, L., Romano, V., De Franceschi, G., Joao Francisco, G. M., Hirokazu Shimabukuro, M., Bougard, B., Aquino, M., 2013. Assessing the GNSS scintillation climate over Brazil under increasing solar activity. J. Atmos. Sol. Terr. Phys., 105, 199-206.

Stolle, C., Lühr, H., Rother, M., Balasis, G., 2006. Magnetic signatures of equatorial spread F as observed by the CHAMP satellite, J. Geophys. Res., 111, A02304, doi:10.1029/2005JA011184 (AGU Editor's Choice: Space Weather - February 2006).

Tramutoli, V., 2007. Robust satellite techniques (RST) for natural and environmental hazards monitoring and mitigation: theory and applications. Proceedings 2007 International Workshop on the Analysis of Multi-temporal Remote Sensing Images, doi:10.1109/MULTITEMP.2007.4293057.

Tramutoli, V. , 2010. Using RST approach and EOS-MODIS radiances for monitoring seismically active regions: a study on the 6 April 2009 Abruzzo earthquake. Natural Hazards and Earth System Sciences, 10, 239-249. 
Tramutoli V., C. Aliano, R. Corrado, C. Filizzola, N. Genzano, M. Lisi, G. Martinelli, N. Pergola, 2013. On the possible origin of thermal infrared radiation (TIR) anomalies in earthquake-prone areas observed using robust satellite techniques (RST), Chemical Geology, 339, 157-168.

Trigunait, A., Parrot, M., Pulinets, S., Li, F., 2004. Variations of the ionospheric electron density during the Bhuj seismic event, Ann. Geophysicae, 22, 4123-4131.

Tsai, Y-B., Liu, J-Y., Ma, K-F., Yen, H-Y., Chen, K-S., Chen, Y-I., and Lee, C-P., 2004. Preliminary results of the iSTEP Program on Integrated Search for Taiwan Earthquake Precursors, TAO, vol. 15, No. 3, 545-562.

Tsallis, C., 1988. Possible generalization of Boltzmann-Gibbs statistics, J. Stat. Phys. 52, 479-487.

Tzanis, A. and F. Vallianatos, 2003. Distributed power-law seismicity changes and crustal deformation in the EW Hellenic Arc, Natural Hazards and Earth Systems Sciences, 3, 179-195.

Uritsky, V. , N. Smirnova, V. Troyan and F. Vallianatos, 2004.Critical dynamics of fractal fault systems and its role in the generation of pre-seismic electromagnetic emissions, Physics \& Chemistry of the Earth, 29, 473-480.

Vallianatos, F. and K. Nomikos, 1998. Seismogenic radioemissions as precursors to earthquakes in Greece, Physics and Chemistry of the Earth, 23/9-10, 953-959.

Vallianatos F. and D. Triantis, , 2008. Scaling in Pressure Stimulated Currents related with Rock Fracture, Physica A, 387, 4940-4946.

Vallianatos, F., A. Nardi, R. Carluccio and M. Chiappini, , 2012. Experimental evidence of a nonextensive statistical physics behavior of Electromagnetic Signals emitted from rocks under stress up to fracture. Preliminary results." Acta Geophysica, 60(3), 894-909.

Vallianatos, F. , G. Michas., G. Papadakis. 2014. Non-extensive and natural time analysis of seismicity before the Mw6.4, October 12, 2013 earthquake in the South West segment of the Hellenic Arc . Physica A: Statistical Mechanics and its Applications, 414:163-173. 
Vallianatos, F. and P. Sammonds, 2013. Evidence of non-extensive statistical physics of the lithospheric instability approaching the 2004 Sumatran-Andaman and 2011 Honshu megaearthquakes, Tectonophysics, 590 , 52-58.

Varotsos, P. A. , N. V. Sarlis, E. S. Skordas, 2011. Natural Time Analysis: The New View of Time. Precursory Seismic Electric Signals, Earthquakes and other Complex Time Series. Springer, pp. 449.

Zhang X., Battiston R., Shen X., Zeren Z., Ouyang X., Qian J., Lin J., Huang J., Miao Y., 2010. Automatic Collecting Technique of Low Frequency Electromagnetic Signals and its application in Earthquake study, in Y. Bi and M.-A. Williams (Eds.), KSEM 2010, LNAI 6291, 366-377.

Zhao, B., Yu, T., Wang, M., Wan, W., Lei, J., Liu, L., Ning, B., 2008. Is an unusual large enhancement of ionospheric electron density linked with the 2008 great Wenchuan earthquake? J. Geophys. Res., 113, A11304, http://dx.doi.org/10.1029/2008JA013613.

Zöller G., Hainzl, S., Kurths K., Zschaua J. , 2002. A Systematic Test on Precursory Seismic Quiescence in Armenia, Nat. Haz., 26, 245-263.

\section{Figure captions}

Fig. 1. The sketch of the concept of integrated (ground and satellite) earthquake monitoring system (adapted from Tsai et al., 2004). The shown satellites are examples of past, present or future space missions.

Fig. 2. Time Difference Distribution (Earthquake time - PB time) for M5+ seismic events and selected PB (NOAA-15,16,17-18; adapted from Battiston and Vitale, 2013). 
Fig. 3. (Left panel:) Distribution of M5+ earthquakes in the L-shell vs. time diagram accessible by the AGILE satellite. The time period is August 5 - September 3, 2007. (Right panel:) an example of preliminary data on the distribution of normalized particle bursts detected by the AGILE satellite above 4 standard deviations during the same period of time (Tavani et al., unpublished material). The event enhancement is in apparent coincidence with the M8 Peru earthquake occurred on August $15,2007$.

Fig. 4. An example of a study of space-time correlation between satellite e.m. anomalies detected by DEMETER and earthquakes (adapted from Němec et al. 2008).

Fig. 5. CHAMP track with a magnetospheric ULF Pc3 wave event (frequency range of Pc3 pulsations: 20-100 $\mathrm{mHz}$ ). From top to bottom, CHAMP filtered magnetic field time series, its corresponding wavelet power spectrum and the combined planar Langmuir probe (PLP) data / magnetic latitude plot, all with respect to time (UT) for a satellite pass from 19:59 to 20:43 UT on 10 April 2006. The bottom row provides additional information about the satellite's magnetic local time (MLT) position. The wave activity is marked with '[EVENT]' (in blue) flags in the lower panel. The latitudes where the ULF activity is observed are also given in blue in the same panel (figure adapted from Balasis et al., 2013a).

Fig. 6. Surface skin temperature (above) mostly detected by satellite and surface air temperature (below) measured by a ground meteorological station in the area above Emilia major Earthquakes on 20 and 29 May 2012. Red vertical arrows represent the time of the major earthquakes, while possible earthquake-related anomalies are indicated by red circles (adapted from Qin et al., 2012). 
Fig. 7. Two-dimensional maps for relative differential TEC (RTEC) obtained from superposition of the GIM maps during interval 00:00-10:00 UT on 3 (storm disturbed) and 9 May (not disturbed) 2008, respectively. The latter is clearly more related to a possible seismic effect to ionosphere (adapted from Zhao et al., 2008).

Fig. 8. VLF spectrogram of an electric field component recorded on 16 January 2009 during one minute between 09:35:00 and 09:36:00 UT. The frequency range is $2.0-2.6 \mathrm{kHz}$. The intensity is color-coded according to the scale on the right. A set of three lines can be observed just above 2 $\mathrm{kHz}$. The frequencies of lines are at 2250, 2350, and $2450 \mathrm{~Hz}$, which means that the frequency interval is equal to $100 \mathrm{~Hz}$. There is no apparent frequency shift of the lines during the observation. The event was measured above Europe. Relatively thin lines forming the event and frequency spacing close to the multiple of base power system frequency $(50 \mathrm{~Hz})$ represent a good indication that the event is caused by PLHR.

Fig. 9. Data recorded on October 21, 2006 between 14.56.30 and 14.59.50 UT. From the top to the bottom the panels show: - the HF spectrogram of an electric component up to $3.33 \mathrm{MHz}$, - the VLF spectrogram of the same component up to $20 \mathrm{kHz}$ (the white line represents the lower hybrid frequency), - the electron density, - the electron temperature, and - the ion temperature as function of the time. A large perturbation is observed in the North of the transmitter NWC $\left(21^{\circ} 47^{\prime} \mathrm{S}\right.$, $\left.114^{\circ} 09^{\prime} \mathrm{E}\right)$.

Fig. 10. Variation of the electron density and spectrograms showing the night emissions on the complete half-orbit 1904.1 on November 10, 2004. One can see large decreases close to the equator which are known as plasma bubbles. The plasma and wave measurement performed by DEMETER inside these bubbles during the very intense storm on 7-11 November 2004 show an important 
turbulence at the low hybrid frequency triggered by electromagnetic whistlers coming from the atmosphere below the satellite. This discovery reveals for the first time the coupling which could exist between the thunderstorms and the ionospheric plasma in the equatorial plasma bubbles.

Fig. 11. (Left) Occurrence of moderate/strong amplitude scintillation (S4 index). (Right) Standard deviation of the TEC rate of change with respect to time (ROT). Both these quantities identify regions where TEC gradients due to the EIA are present (adapted from Spogli et al., 2013).

Fig. 12. Occurrence of moderate/strong phase scintillation above European high latitude region along year 2008 (low solar activity) as a function of the magnetic latitude and magnetic local time. Top plot is for IMF Bz positive conditions, while bottom plot is for negative conditions. Black and red curves reproduce the modeled auroral ovals (Feldstein model) for quiet (IQ=0) and moderately disturbed (IQ=3) geomagnetic conditions, respectively (adapted from Alfonsi et al., 2011).

Fig. 13: Example of particle precipitation induced by a lightning stroke on July 9, 2005. The top panel shows a spectrogram between 0 and $20 \mathrm{kHz}$ obtained with an electric component. The vertical trace around 21:04:53 UT is the electromagnetic mark of a lightning stroke which occurred in the atmosphere. At the same time one can see on the bottom panel which display the IDP data an increase of the particle flux up to $200 \mathrm{keV}$.

Fig. 14. The top panel represents the spectrogram of an electric field component from 0 to $20 \mathrm{kHz}$ on September 02, 2005 between 04:29:00 and 04:37:00 UT. The intensity is color-coded according to the color scale on the right. The bottom panel represents the variation of the $\mathrm{O}^{+}$ion density (the densities of the other ions are much lower). The information at the bottom of the figure is related to the Universal Time, the Local Time, the geographic latitude and longitude, and the McIlwain parameter L. 
Figure 1.

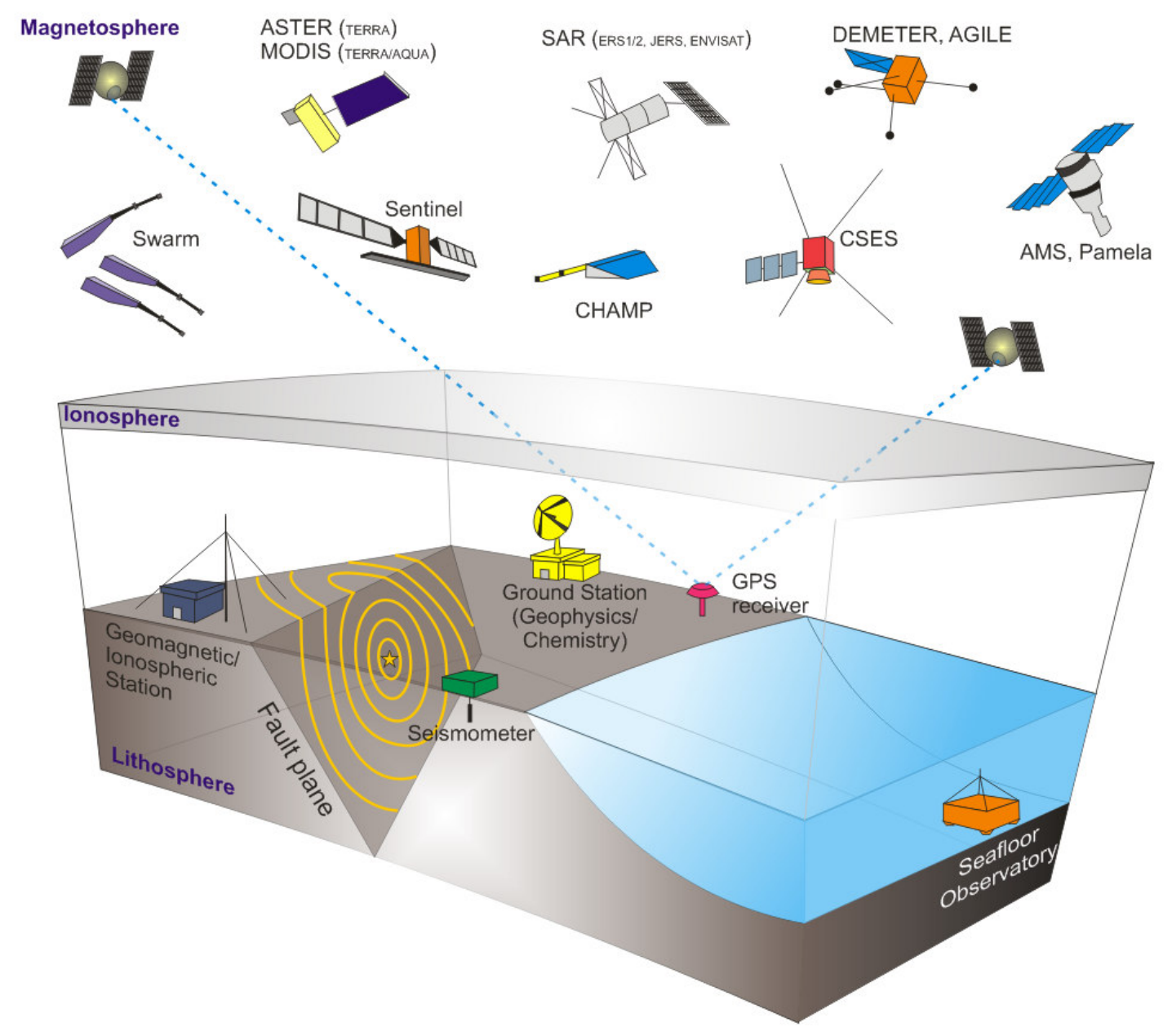


Figure 2.

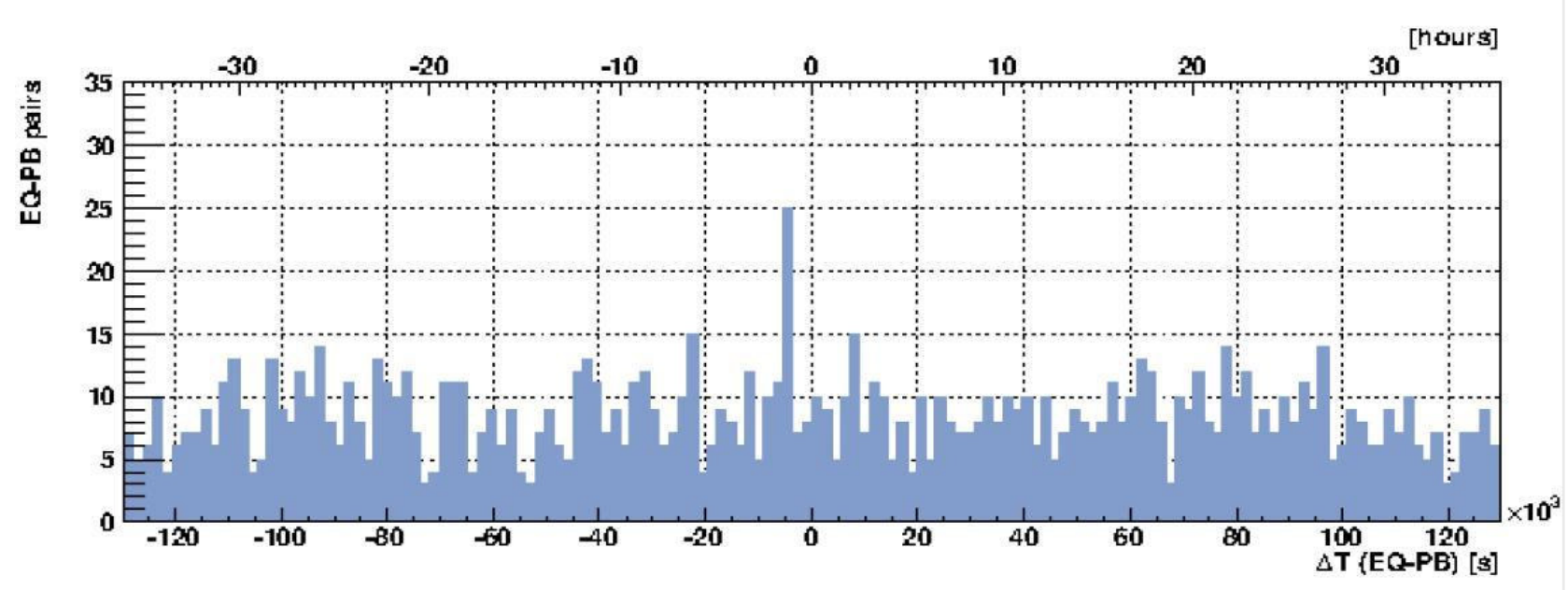


Figure 3.
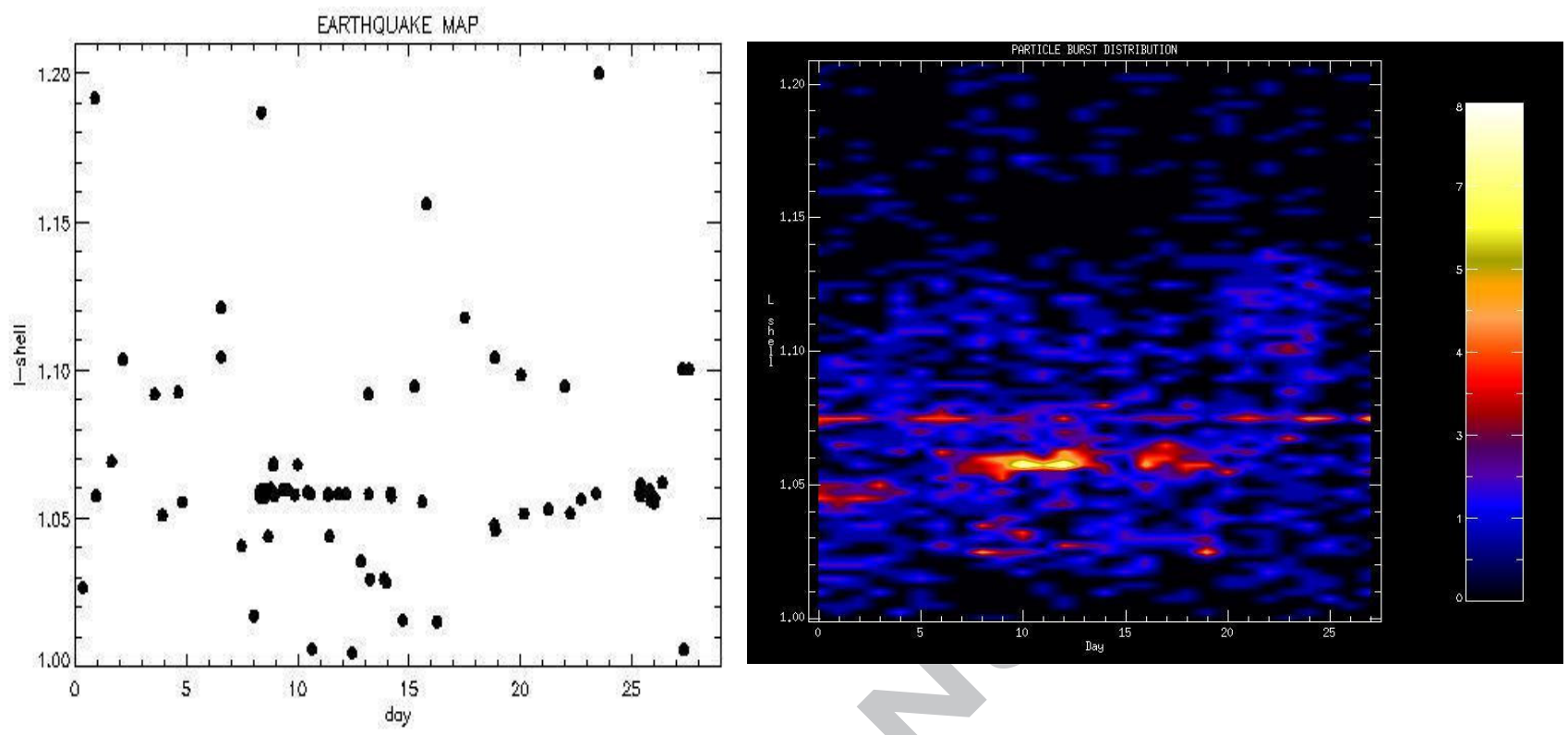
Figure 4.
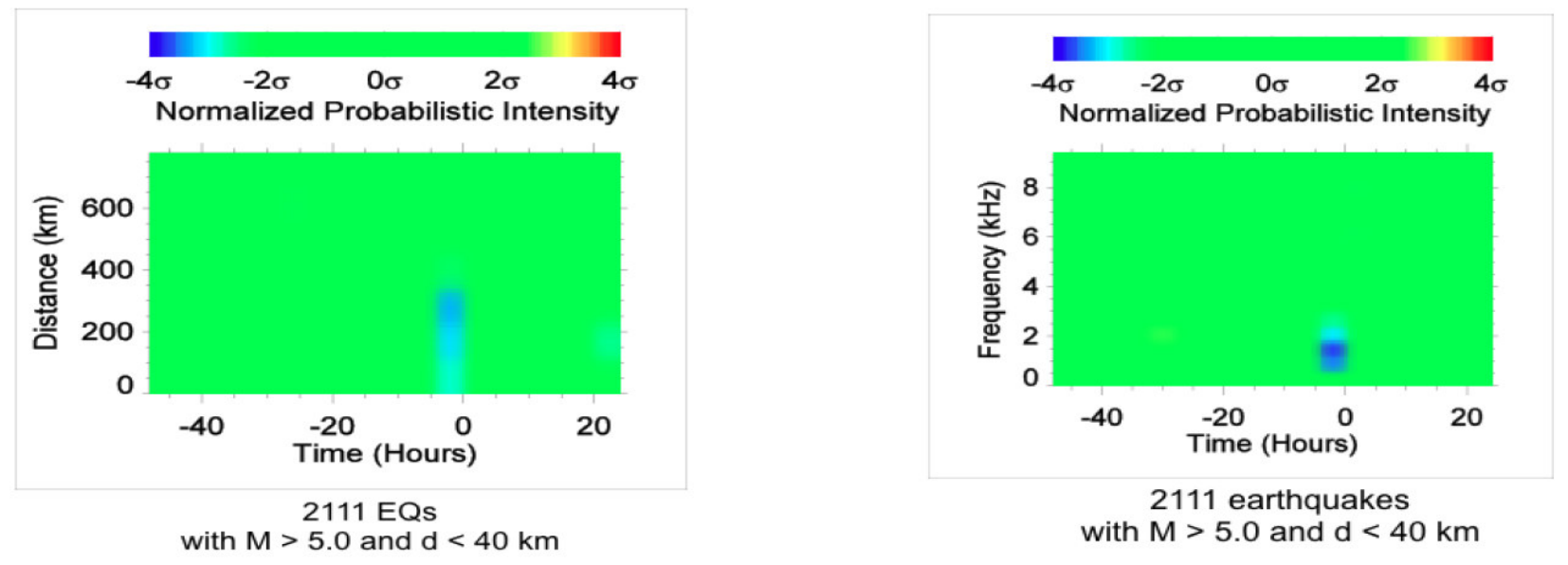

Figure 5. 

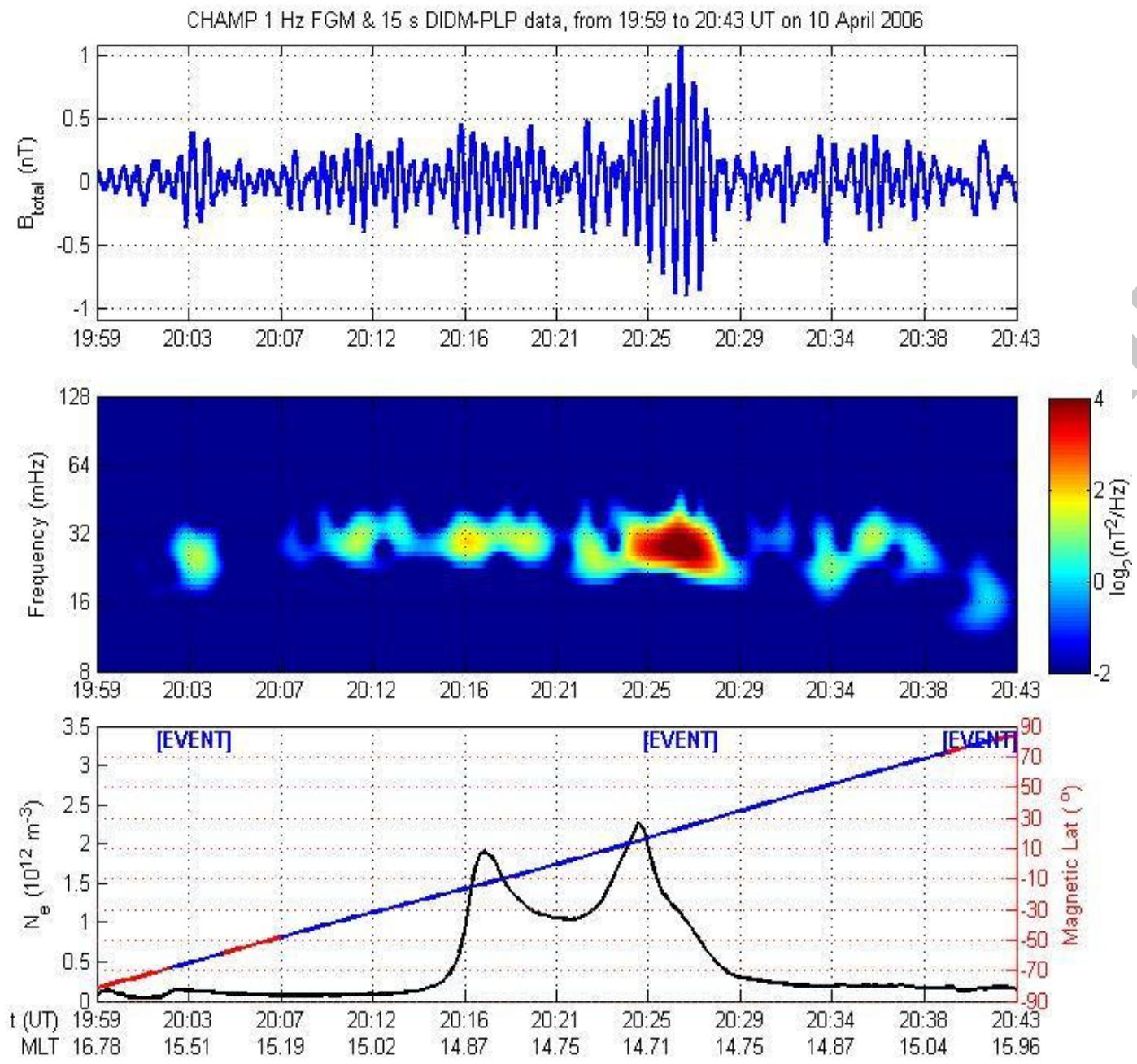

Figure 6. 

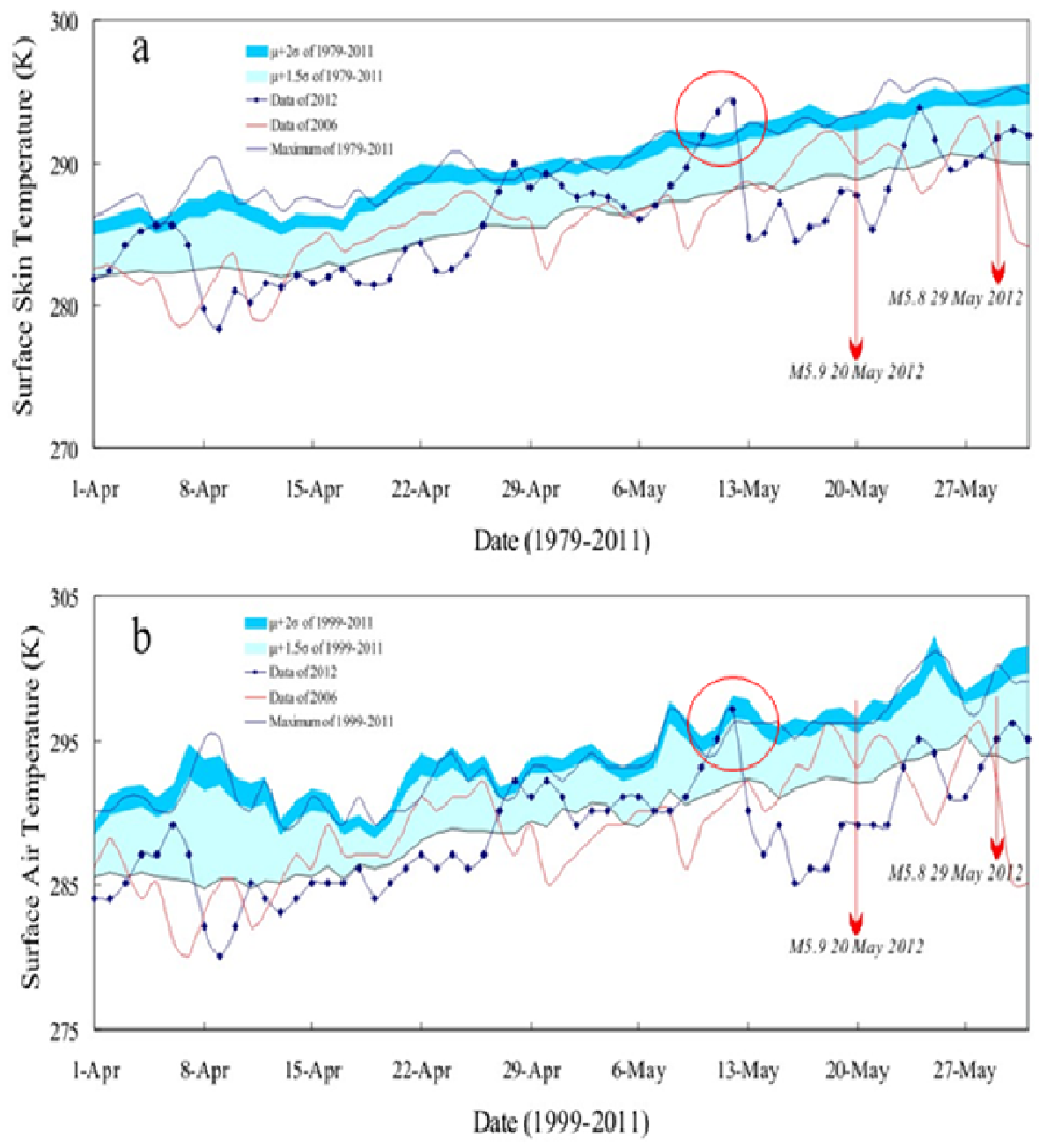
Figure 7.
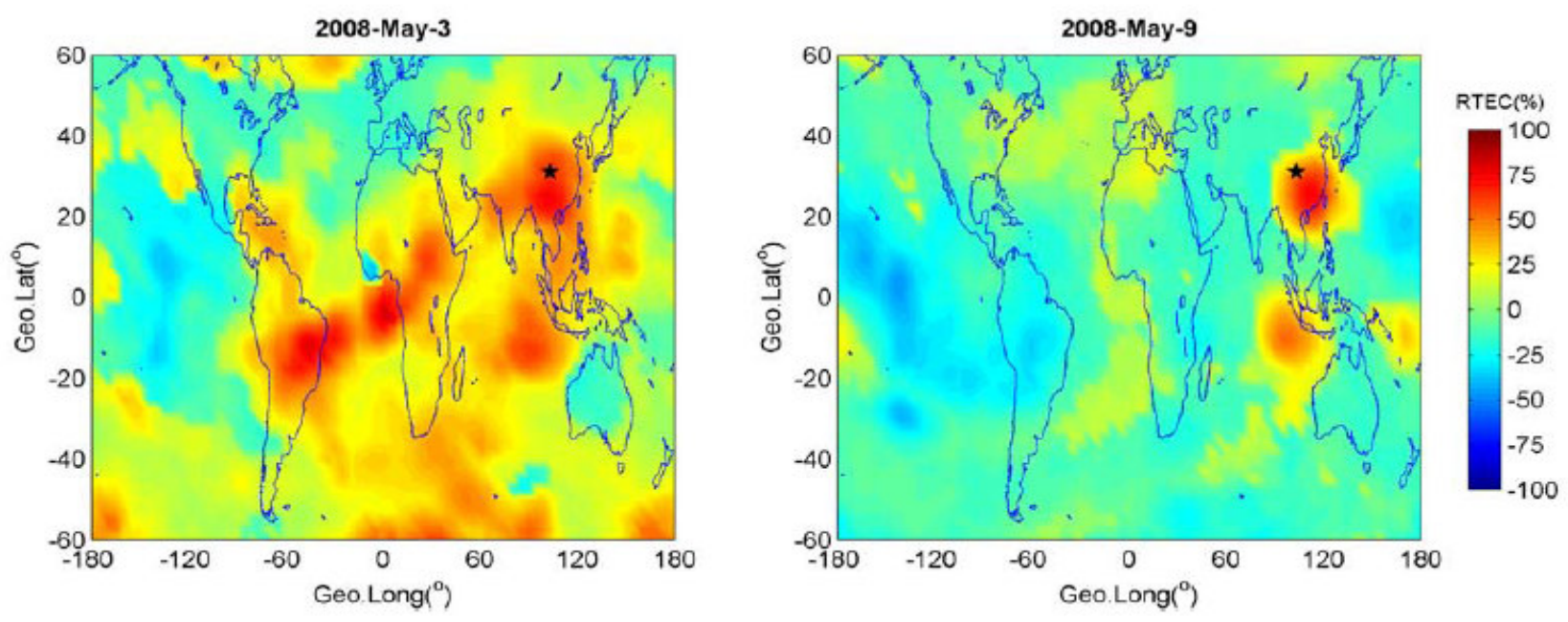
Figure 8.

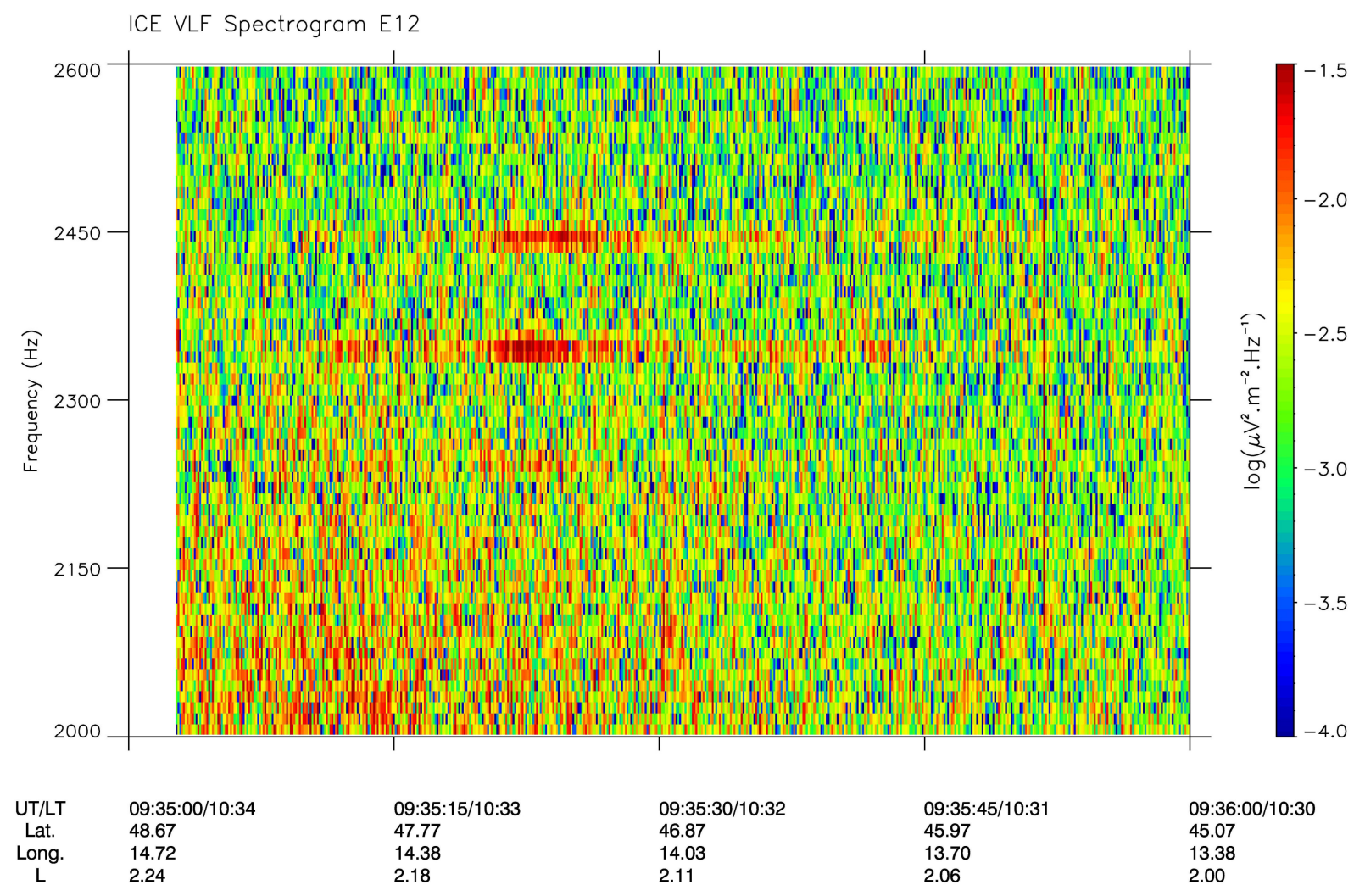

Figure 9. 

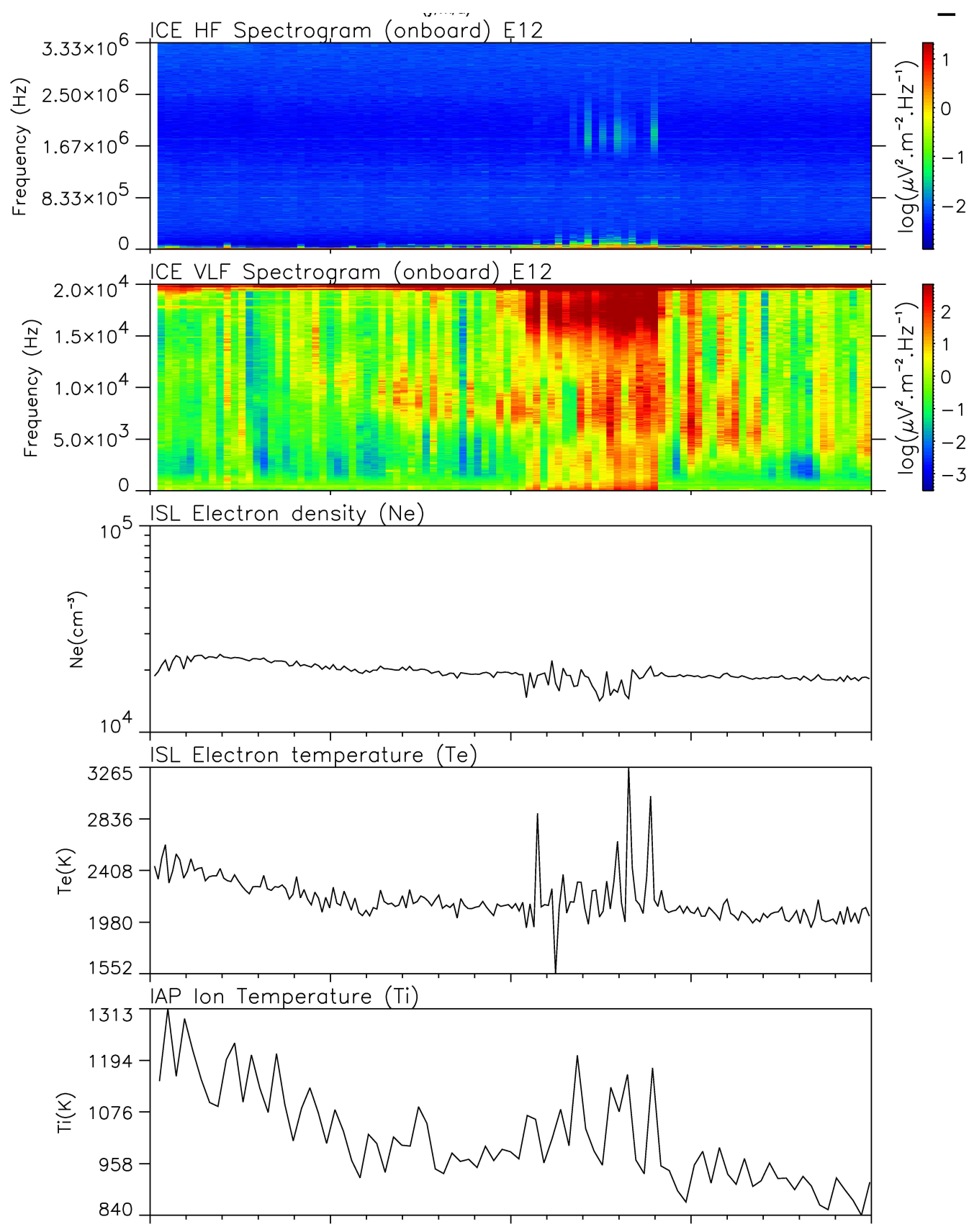

$\begin{array}{clllll}\text { UT/LT } & 14: 56: 30 / 22: 32 & 14: 57: 20 / 22: 30 & 14: 58: 10 / 22: 28 & 14: 59: 00 / 22: 26 & 14: 59: 50 / 22: 24 \\ \text { Lat. } & -25.97 & -22.95 & -19.93 & -16.90 & -13.88 \\ \text { Long. } & 113.92 & 113.19 & 112.49 & 111.81 & 111.14 \\ \text { L } & 1.68 & 1.54 & 1.42 & 1.33 & 1.25\end{array}$

Figure 10. 

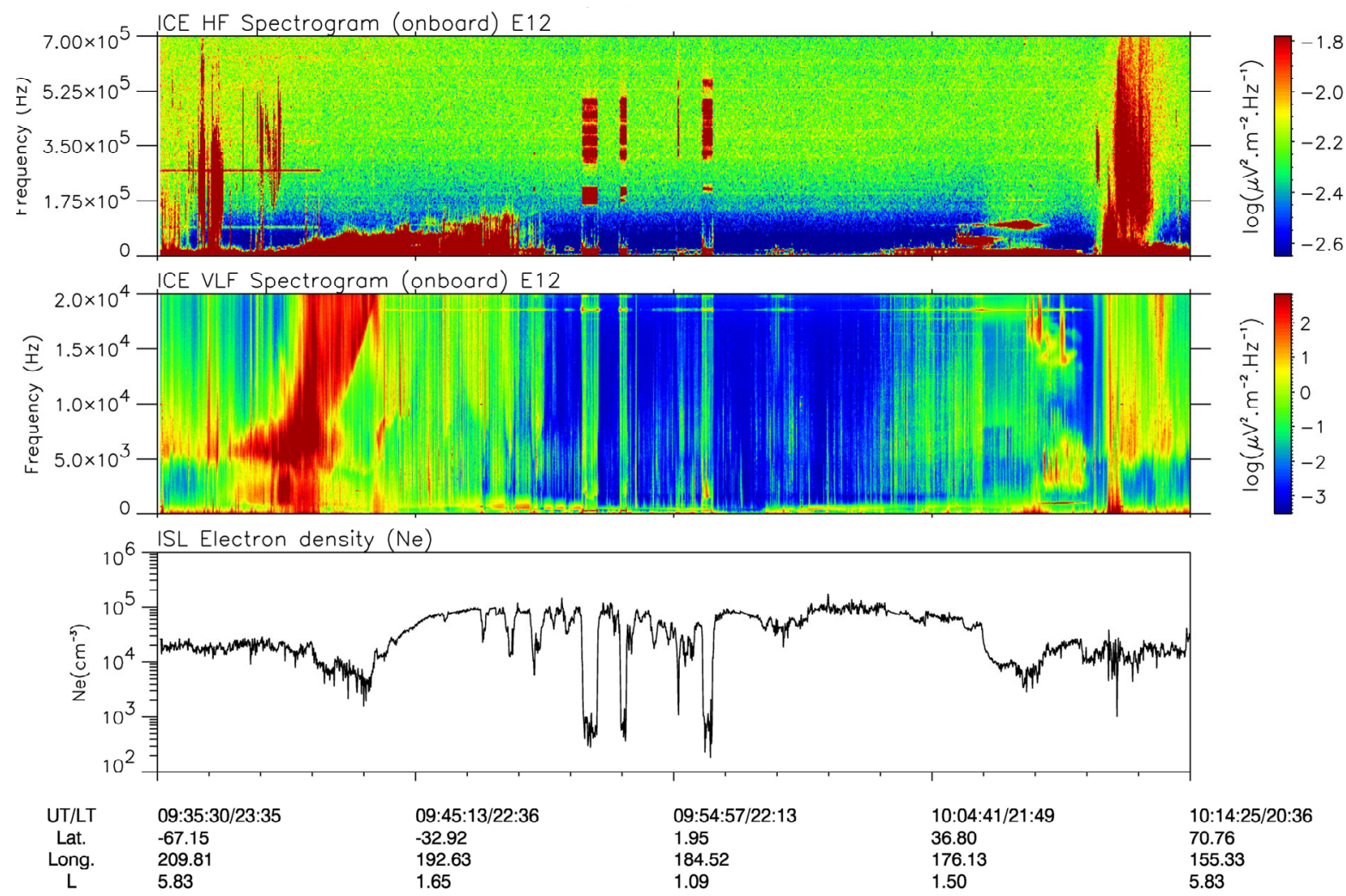
Figure 11.

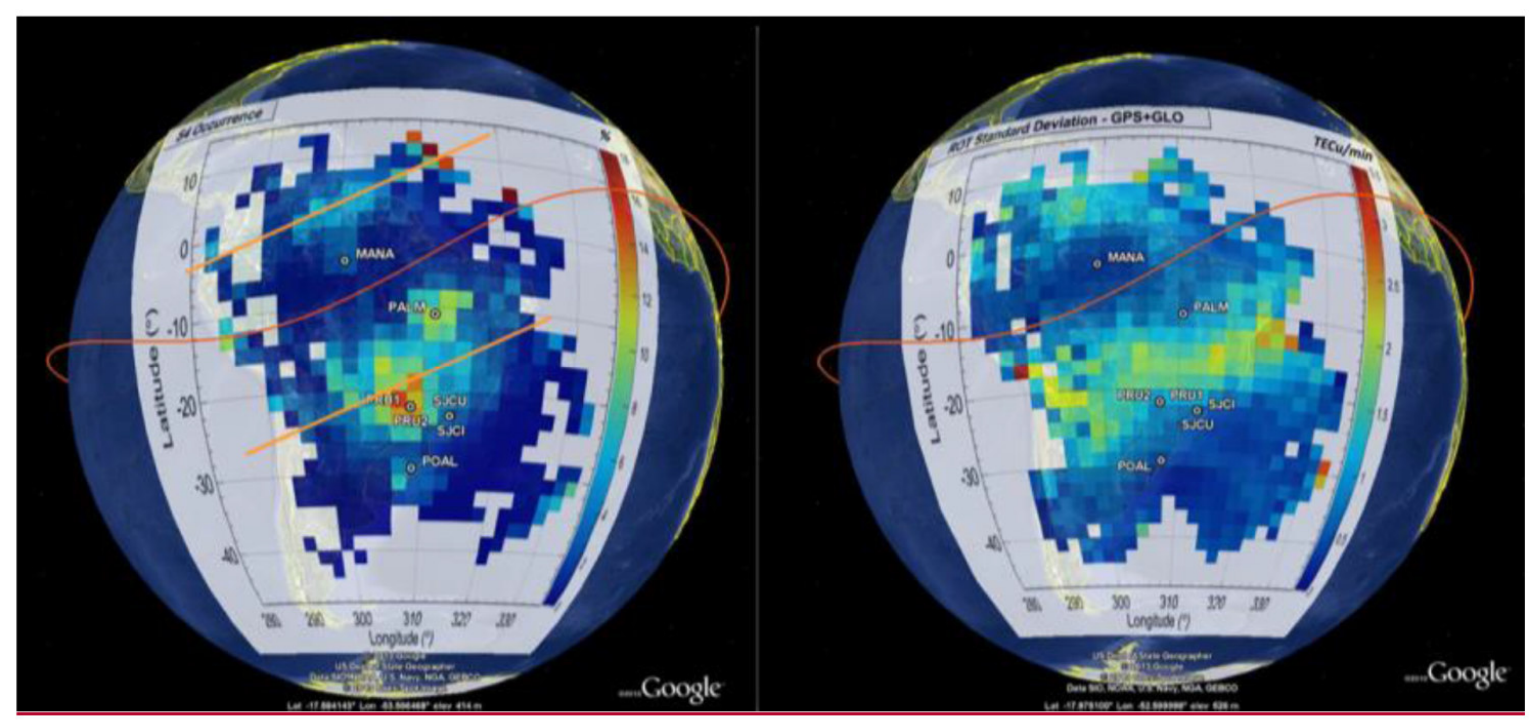


Figure 12.
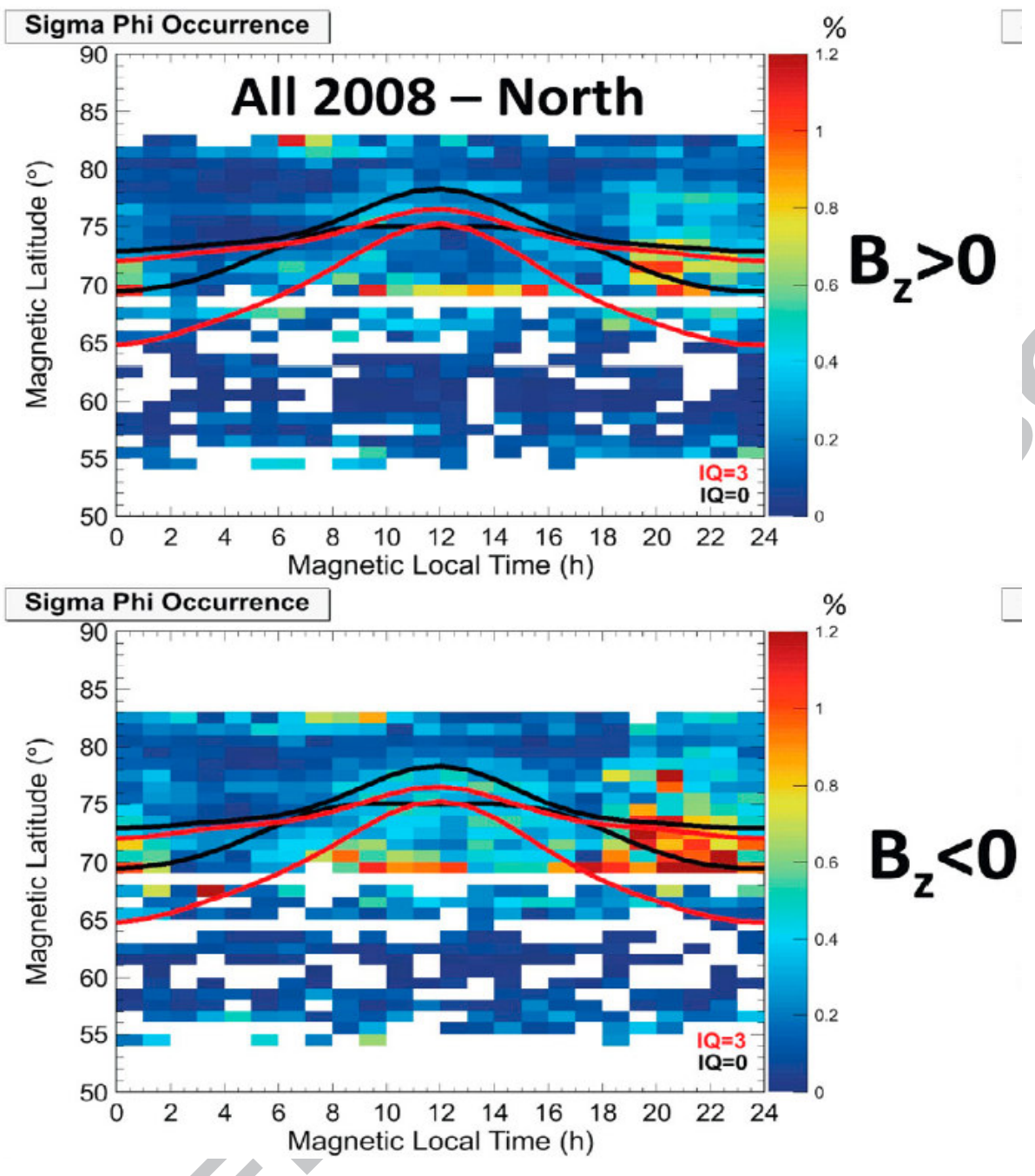

Figure 13. 

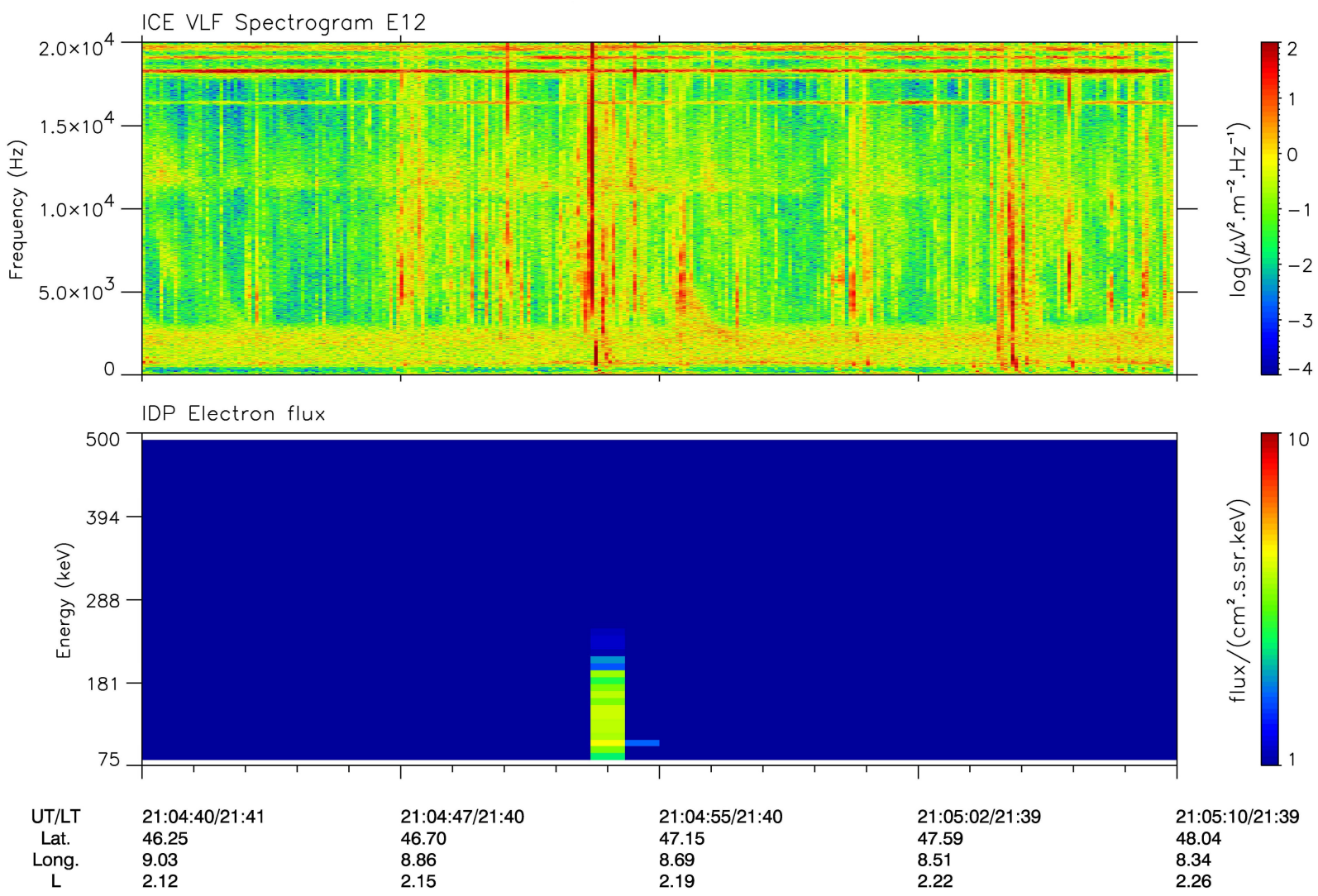
Figure 14.
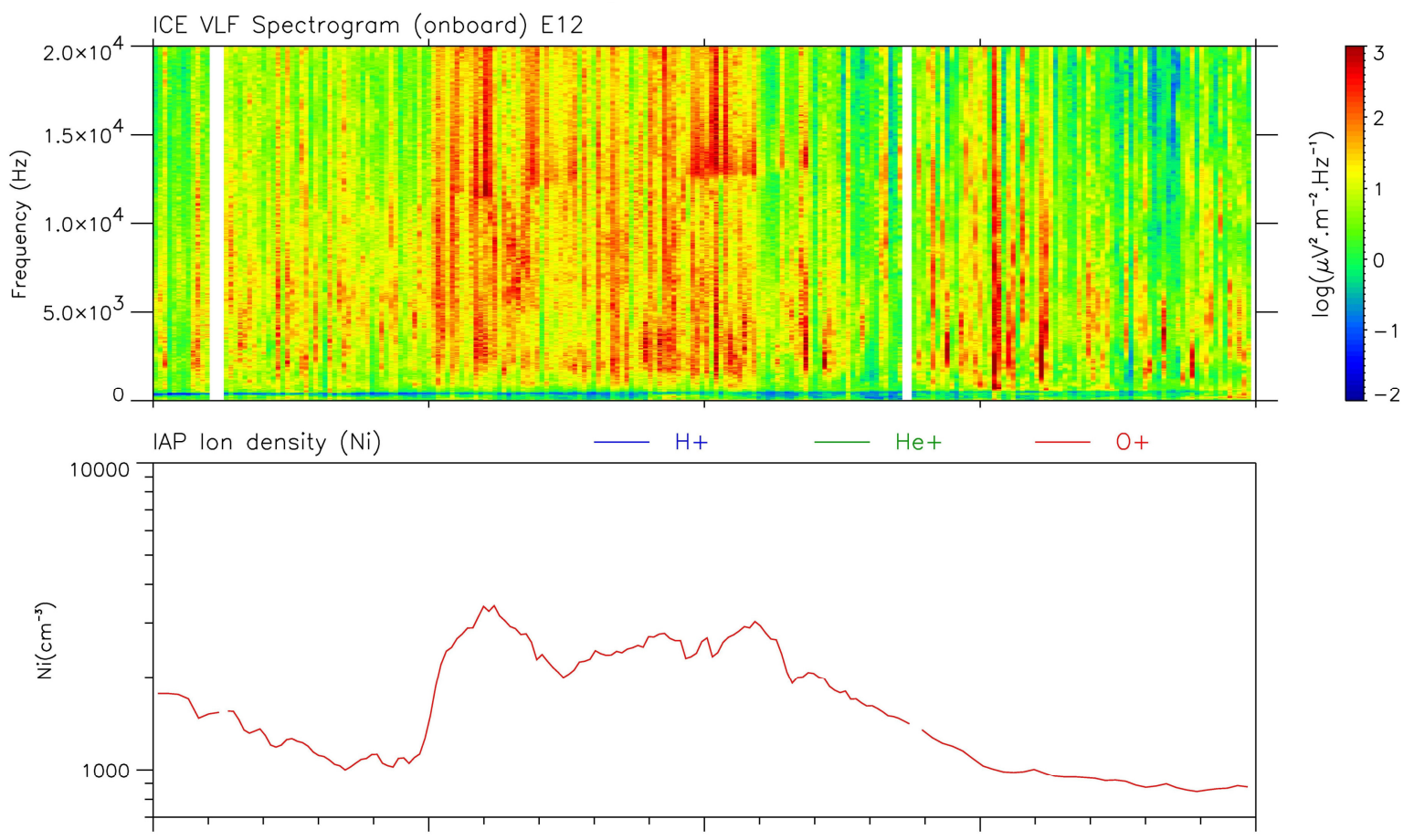

$\begin{array}{cllll}\text { UT/LT } & 04: 29: 00 / 22: 16 & 04: 31: 00 / 22: 12 & 04: 33: 00 / 22: 08 & 04: 35: 00 / 22: 03 \\ \text { Lat. } & -0.73 & 6.47 & 13.68 & 20.89 \\ \text { Long. } & 266.81 & 265.26 & 263.69 & 262.04 \\ \text { L } & 1.13 & 1.20 & 1.31 & 1.49\end{array}$




\section{Highlights:}

- State of the art of the lithosphere-atmosphere-ionosphere coupling (LAIC) mechanisms

- Earthquake-related case studies are shown together with unrelated cases

- Models of LAIC are proposed with future trends of research 